\title{
A Review on Diffusion Bonding between Titanium Alloys and Stainless Steels
}

\author{
De-feng Mo, ${ }^{1}$ Ting-feng Song, ${ }^{2}$ Yong-jian Fang, ${ }^{2}$ Xiao-song Jiang $\mathbb{C}^{2},{ }^{2}$ Charles Q. Luo, ${ }^{3}$ \\ Machael D. Simpson, ${ }^{3}$ and Zhi-ping Luo $\mathbb{D}^{3}$ \\ ${ }^{1}$ Key Laboratory of Infrared Imaging Materials and Detectors, Shanghai Institute of Technical Physics, \\ Chinese Academy of Sciences, Shanghai 200083, China \\ ${ }^{2}$ School of Materials Science and Engineering, Southwest Jiaotong University, Chengdu, Sichuan 610031, China \\ ${ }^{3}$ Department of Chemistry and Physics, Fayetteville State University, Fayetteville, NC 28301, USA \\ Correspondence should be addressed to Xiao-song Jiang; xsjiang@home.swjtu.edu.cn and Zhi-ping Luo; zluo@uncfsu.edu
}

Received 24 May 2018; Accepted 9 August 2018; Published 20 September 2018

Academic Editor: Yee-wen Yen

Copyright (c) 2018 De-feng Mo et al. This is an open access article distributed under the Creative Commons Attribution License, which permits unrestricted use, distribution, and reproduction in any medium, provided the original work is properly cited.

\begin{abstract}
High-quality joints between titanium alloys and stainless steels have found applications for nuclear, petrochemical, cryogenic, and aerospace industries due to their relatively low cost, lightweight, high corrosion resistance, and appreciable mechanical properties. This article reviews diffusion bonding between titanium alloys and stainless steels with or without interlayers. For diffusion bonding of a titanium alloy and a stainless steel without an interlayer, the optimized temperature is in the range of $800-950^{\circ} \mathrm{C}$ for a period of 60-120 min. Sound joint can be obtained, but brittle FeTi and Fe-Cr-Ti phases are formed at the interface. The development process of a joint mainly includes three steps: matching surface closure, growth of brittle intermetallic compounds, and formation of the Kirkendall voids. Growth kinetics of interfacial phases needs further clarification in terms of growth velocity of the reacting layer, moving speed of the phase interface, and the order for a new phase appears. The influence of $\mathrm{Cu}, \mathrm{Ni}$ (or nickel alloy), and Ag interlayers on the microstructures and mechanical properties of the joints is systematically summarized. The content of FeTi and Fe-Cr-Ti phases at the interface can be declined significantly by the addition of an interlayer. Application of multi-interlayer well prevents the formation of intermetallic phases by forming solid solution at the interface, and parameters can be predicted by using a parabolic diffusion law. The selection of multi-interlayer was done based on two principles: no formation of brittle intermetallic phases and transitional physical properties between titanium alloy and stainless steel.
\end{abstract}

\section{Introduction}

Recently, by virtue of relatively low cost, lightweight, high corrosion resistance, and appreciable mechanical properties, high-quality joints between titanium alloy and stainless steel have found applications for nuclear fuel field, petrochemical, cryogenic protector, and aerospace industries [1-7]. Titanium alloys possess low densities, high strengths, and strong heat resistance, enabling them for a wide range of applications in petrochemical, aviation, and space industries [5]. For instance, when aircrafts work at super-high speeds, their engine and surface temperatures are quite high where titanium alloy is more suitable than an aluminum alloy or other lightweight metal alloys because titanium alloy maintains very good strength and stability in relatively high- temperature atmosphere. They can be bonded with many kinds of steels to achieve multi-functional applications $[4,5]$. $316 \mathrm{~L}(\mathrm{Fe}-18 \mathrm{Cr}-11 \mathrm{Ni})$ stainless steel is widely used for its relatively low cost and low corrosion rate which is attributed to inner chromium oxide region and outer mixed ironnickel oxide region [8]. However, achieving a strong bonding of titanium/steel bimetallic structures is restricted by two aspects. Firstly, the significant difference on physical properties, such as thermal expansion coefficient, density, and thermal conductivity, can lead to large residual stress and microstructural inhomogeneity at the interfacial region of the titanium alloy and stainless steel [9-11]. Secondly, metallurgical incompatibilities of them are prone to form brittle intermetallic compounds at a welding pool. For example, according to the TiFe binary phase diagram, the 
solid solubility of Fe in Ti is less than 0.1 at.\%, and thus TiFe and $\mathrm{TiFe}_{2}$ phases are formed at the bonded joints where cracks are liable to emerge and propagate spontaneously $[6,11-15]$.

In order to solve these problems, many welding methods have been practiced to investigate the joining between titanium alloys and stainless steels, mainly including brazing welding [7, 16-20], laser welding [2, 5, 6, 21-25], electronbeam welding [26-31], diffusion bonding [32-36], explosive welding [37-40], and friction stir welding [41-47]. Cu-based and Ag-based fillers were usually used to braze titanium/steel joints, while scattered brittle intermetallics, such as $(\mathrm{Fe}, \mathrm{Cu}) \mathrm{Ti}$, $\mathrm{Cu}_{4} \mathrm{Ti}_{3}$, and $\mathrm{CuTi}[20,48]$ and $\mathrm{Cu}_{4} \mathrm{Ti}$ and $\mathrm{CuTi}_{2}$ [7], were induced to the interfaces which were detrimental to the mechanical properties of the joints, and maximum possible tensile strength of the joints was found to be no more than $200 \mathrm{MPa}[16-20,48]$. Without the interlayer, sound joints are hard to be obtained by direct laser welding or electronbeam welding because of continuously distributed brittle TiFe intermetallics and high residual stress at the welding pool [21, 25, 49-52]. Continuous wave laser was used to weld titanium and stainless steel, while $\mathrm{Fe}_{0.2} \mathrm{Ni}_{4.8} \mathrm{Ti}_{5}, \mathrm{Cr}_{2} \mathrm{Ti}$, and NiTi phases were formed which resulted in extensive cracking at the interface [13]. By adjusting the beam offset toward the titanium alloy side, tensile strength of the joint can be improved, but FeAl, FeTi, $\mathrm{Fe}_{2} \mathrm{Ti}$, and $\mathrm{Ti}_{5} \mathrm{Fe}_{17} \mathrm{Cr}_{5}$ phases still exist at the interface [25]. As welded by laser welding, when joining titanium alloy and stainless steel by electron-beam welding without an interlayer, TiFe phases led to great brittleness and the joint cracked spontaneously under thermal stress [52].

Comparatively, solid-state joining process is more appropriate for welding of dissimilar materials with striking various physical and metallurgical properties. Diffusion bonding, explosive welding, and friction stir welding have been successfully used to join dissimilar structures, such as $\mathrm{Ti} / \mathrm{Fe}$ [53], $\mathrm{Al} / \mathrm{Fe}$ [54], $\mathrm{Cu} / \mathrm{Ti}$ [55], $\mathrm{Cu} / \mathrm{Fe}$ [56], and $\mathrm{Al} / \mathrm{Mg}$ [57], focusing on mechanical properties and the influence of parameters on the morphology and microstructural changes at the interfaces. Liu et al. [57] successfully bonded Mg/Al by vacuum diffusion bonding. Al-based solid solution, $\mathrm{Al}_{3} \mathrm{Mg}_{2}$, $\mathrm{Al}_{12} \mathrm{Mg}_{17}$, and $\mathrm{Mg}$-based solid solution constitute the joint. Kundu and Chatterjee [58] applied $\mathrm{Al}$ as an interlayer to complete diffusion bonding of titanium and $18 \mathrm{Cr}-8 \mathrm{Ni}$ stainless steel. $\mathrm{Al}_{2} \mathrm{Fe}, \mathrm{AlTi}$, and $\mathrm{Al}_{3} \mathrm{Ti}$ were observed at the interface, and the maximum tensile strength was up to $266 \mathrm{MPa}$ for the joint sample processed at $650^{\circ} \mathrm{C}$ for $90 \mathrm{~min}$. Muralimohan et al. [59] joined cylindrical pure $\mathrm{Ti}$ to 304 stainless steel by friction welding with nickel as the interlayer, and $\mathrm{NiTi}, \mathrm{Ni}_{3} \mathrm{Ti}, \mathrm{NiTi}_{2}$, and $\mathrm{Ni}_{2} \mathrm{Ti}$ intermetallic compounds were demonstrated at the joints instead of brittle TiFe intermetallic compounds. Chu et al. [38] welded a flyer Ti plate towards a mild steel plate by explosive welding. It was found that extremely rapid temperature increase and high cooling rates attributed to the deformation, recovery, and recrystallization of the joint, and $\mathrm{Fe}_{2} \mathrm{Ti}$ and $\mathrm{FeTi}$ phases were formed at the interface. Among these welding methods, diffusion bonding is restricted less by the shape of samples and minimal effect of temperature gradient, with the option to supply a vacuum atmosphere easily that solves the problem of the reactive nature of titanium alloys with oxygen, nitrogen, and hydrogen in air.

Diffusion bonding is a near net shape joining process, in which a way the contact surfaces achieve porosity closure via creep and atom diffusion under certain temperature and pressure [32-36, 60-62]. Research has been conducted to investigate the influence of bonding temperature, bonding time, and loaded pressure on the manufacture of titanium/steel bimetallic structures $[33,34]$. When an interlayer is introduced into the diffusion bonding of titanium/steel structure, the mechanical properties of the joints can be improved significantly. However, how to understand the mechanism of different interlayers on the joining of titanium/steel still needs further clarification. Therefore, in this text, the diffusion bonding between titanium alloy and stainless steel without and with interlayer will be reviewed. The influences of different interlayers on the microstructures and mechanical properties of the joints will be summarized and compared. In addition, regularity of the joint bonded by diffusion bonding is reviewed, and the development trend of dissimilar joins between titanium alloys and stainless steels by diffusion bonding is forecasted.

\section{Diffusion-Bonded Joints without Interlayer}

2.1. Microstructure of Interface. In order to restrain the formation of intermetallics at the interface, low-temperature diffusion bonding between titanium alloy and stainless steel was carried out. Velmurugan et al. [60] conducted diffusion bonding of Ti-6Al-4V and duplex stainless steel in a lower temperature of $650^{\circ} \mathrm{C}$ to $800^{\circ} \mathrm{C}$ for $30 \mathrm{~min}$. At the interface, $\alpha$-Fe $+\lambda$ (solid solution of $\mathrm{Fe}_{2} \mathrm{Ti}+\mathrm{Cr}_{2} \mathrm{Ti}$ ), $\lambda+\mathrm{FeTi}$, and $\beta$ - Ti were formed; and at a higher bonding temperature, the width of these reaction phases increased. When the bonding temperature reached up to $750^{\circ} \mathrm{C}$, the maximum shear strength value of $194.3 \mathrm{MPa}$ was obtained. Ghosh and Chatterjee [61] studied joints bonded by pure titanium and austenitic stainless steel at a temperature range of $850-950^{\circ} \mathrm{C}$ for 60 min, mainly with $\sigma, \mathrm{Fe}_{2} \mathrm{Ti}, \mathrm{FeTi}$, and $\mathrm{Fe}_{2} \mathrm{Ti}_{4} \mathrm{O}$ phases residing at the interface. A typical morphology of the interface is shown in Figure 1, which includes three areas, namely, a black zone with intermetallics, bright $\beta$-Ti layer, and acicular $\alpha-\beta$ Ti layer.

Vigraman et al. [62] used EDAX (energy dispersive X-ray analysis) and XRD (X-ray diffraction) to identify the compounds presented at the joints of diffusion-bonded Ti-6Al-4V and AISI 304L, and apart from the presence of $\mathrm{Fe}_{2} \mathrm{Ti}, \mathrm{TiNi}_{2}$, $\mathrm{Ti}_{3} \mathrm{Ni}_{4}$, and $\mathrm{Fe}_{2} \mathrm{Ti}_{4} \mathrm{O}$, additional $\mathrm{Fe}_{2} \mathrm{~V}_{3}, \mathrm{Mn}_{2} \mathrm{Ti}, \mathrm{Fe}_{3} \mathrm{Al}_{2} \mathrm{Si}_{4}$, $\mathrm{Al}_{6} \mathrm{Ti}_{19}, \mathrm{Al}_{4} \mathrm{CrNi}_{15}$, and $\mathrm{Ti}_{2} \mathrm{Si}_{2}$ phases were also confirmed at the interface due to the aggregation of $\mathrm{V}, \mathrm{Mn}, \mathrm{Si}$, and $\mathrm{Al}$. The formation of these phases at the interface resulted in the absence of related elements at the grain boundaries, and thus grain growth took place. Miriyev et al. [63] inserted $\mathrm{Ti}$ as the interlayer to bond steel and aluminum. At the interface of $\mathrm{Ti}$ steel, ferritic structure presents at the titanium carbide layer, which indicates local decarburization.

Figure 2 illustrates the concentration profiles from EPMA (electron probe microanalyzer) analysis of elements 


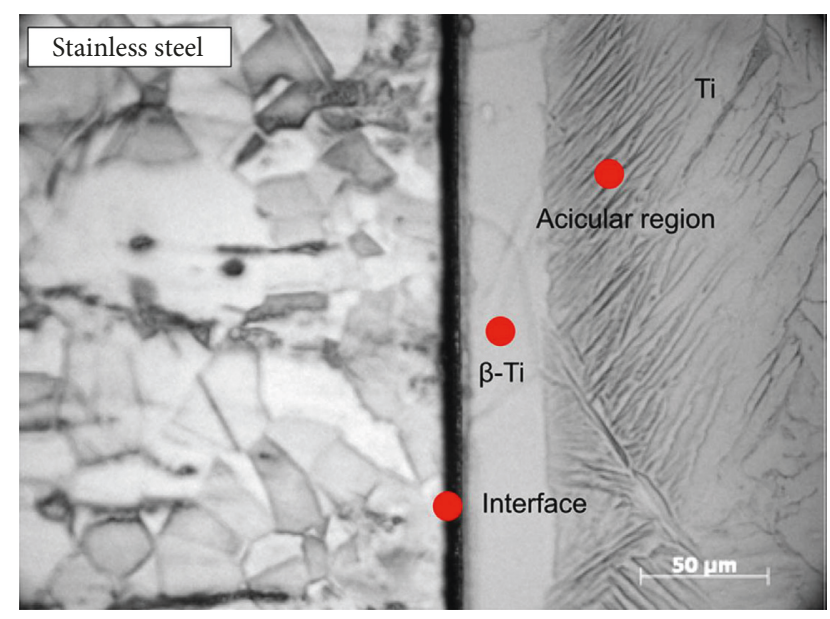

FIgURe 1: A typical morphology of bonded joint between Ti grade 2 and AISI 321 stainless steel. A black interface with intermetallics, bright $\beta$-Ti layer and acicular $\alpha$ - $\beta$ Ti layer (reproduced from [34] with permission).

Ti, Fe, Ni, Cr, and Mo along with a BSE (backscattered electron) image of a region at Ti-6Al-4V (TiA) and $316 \mathrm{~L}$ stainless steel joint interface bonded at $900^{\circ} \mathrm{C}$ for $120 \mathrm{~min}$. It can be seen from Figure 2(a) that the interface is divided into three parts, including layer $\mathrm{A}$, layer $\mathrm{B}$, and dark $\beta$-Ti layer. By comparing the distribution of elements in Figures 2(b)-2(f), layer A is mainly composed of Fe and Cr. According to the EDS (energy dispersion spectroscopy) result, the content of $\mathrm{Ti}$ is only 3.2 at.\%, while that of $\mathrm{C}$ reaches up to 18.8 at.\%. It is deduced that during the bonding process, carbon atoms diffuse into layer $\mathrm{A}$ and aggregate to form $(\mathrm{Fe}, \mathrm{Cr})_{3} \mathrm{C}$ phase. In addition, there is also aggregation of Mo atoms at layer A, which weakens the pinning effect on grain boundaries. Layer B consists of Ti (44.8 at.\%), Fe (29.4 at.\%), C (18.8 at.\%), and little $\mathrm{Ni}$ element and possible phases of this layer are $\mathrm{TiC}$ and TiFe phases. The formation of the $\beta$-Ti layer is due to the diffusion of $\mathrm{Fe}$ and $\mathrm{Ni}$ into the titanium alloy side. Fe and $\mathrm{Ni}$ are $\beta$-stabilizing element to titanium alloy, which results in hightemperature $\beta$ phase to retain at room temperature. Ghosh and Chatterjee [61] confirmed that diffusion distance of $\mathrm{Ti}$ in stainless steel side was minimal, while $\mathrm{Fe}, \mathrm{Cr}$, and $\mathrm{Ni}$ atoms possessed comparatively larger diffusional distances in the $\mathrm{Ti}$ side. Ti is a fast diffusing specie, and fast diffusion of Ti creates a large number of vacancies in its matrix and thus promotes long diffusional distances of $\mathrm{Fe}, \mathrm{Cr}$, and $\mathrm{Ni}$ on the $\mathrm{Ti}$ side.

Mukherjee et al. [34] employed shrinkage-stress formed at the cooling process to minimize the content of intermetallic compounds at the interface of Ti grade 2 and AISI 321 stainless steel. Width of diffusion was shortened, and the formation of FeTi at the interface was reduced. Meanwhile, the $\mathrm{Fe}_{2} \mathrm{Ti}$ phase was eliminated. Kundu et al. [64] examined that when the bonding temperature was $900^{\circ} \mathrm{C}$ for $45 \mathrm{~min}$, joints fractured at the $\lambda+\mathrm{FeTi}$ phase, with the existence of the cleavage pattern indicating brittle nature. When processed at and above $950^{\circ} \mathrm{C}$, failure of bonded joints happened through the $\sigma$ phase. Fracture morphology of the bonded joints at different temperatures is shown in Figure 3. Matching surface closure by diffusion of atoms and reaction products promotes the joining of bimetallic structures, as presented in Figure 3(a). Properties of joints are dominated by interfacial porosity. In Figures 3(b)-3(c), brittle intermetallic compounds are growing and the width of them governs the strength of joints. After this, due to the Kirkendall effect, voids are formed near the interface region, which further diminishes the mechanical property, as illustrated in Figure 3(d) [60-64]. It can be concluded that the strength of bonded joints are controlled by interfacial porosity and brittle intermetallic compounds.

In conclusion, the microstructure of diffusion-bonded joints of titanium alloy and stainless steel without the interlayer is mainly determined by three factors: bonding temperature, bonding time, and composition of raw materials. Lower bonding temperature can restrain the content of brittle intermetallics, such as $\mathrm{FeTi}, \mathrm{Fe}_{2} \mathrm{Ti}, \lambda$, and $\sigma$, at the interface, but the strength of the joints is limited. For diffusion bonding of titanium alloy and stainless steel without the interlayer, the optimized temperature is in the range of $800-950^{\circ} \mathrm{C}$ for a period of 60-120 min. When applying higher bonding temperature, based on Fick's second law, shorter bonding time favors achieving higher strength and vice versa. The composition of titanium alloy and stainless steel also has an obvious influence on the kinds of intermetallics formed at the joints. The aggregation of $\mathrm{V}$ and $\mathrm{Al}$ from titanium alloy and $\mathrm{C}, \mathrm{Mn}$, and $\mathrm{Si}$ from stainless steel during diffusion bonding can give rise to the formation of $\mathrm{TiC}, \mathrm{Fe}_{2} \mathrm{~V}_{3}, \mathrm{Mn}_{2} \mathrm{Ti}, \mathrm{Fe}_{3} \mathrm{Al}_{2} \mathrm{Si}_{4}$, and $\mathrm{Al}_{6} \mathrm{Ti}_{19}$ at the intermetallic layer. The process of diffusion boding without the interlayer can be summarized as follows: the first stage is the matching surface closure by diffusion of atoms at certain temperature, and reaction products formed promote the joining of bimetallic structures. The second stage is the formation of brittle intermetallic compounds, and the width of them governs the strength of joints. Due to the Kirkendall effect, the third stage is the formation of voids near the interface region, which further diminishes the mechanical property.

2.2. Growth Kinetics of Interfacial Phases. Ferrante and Pigoretti [33] researched the influence of diffusion bonding temperature and bonding time on interfacial microstructure and mechanical strength of titanium alloy (Ti-6A1-4V) to AISI 316L stainless steel. The results showed that the growth of interfacial intermetallic compounds obeyed the quadratic law and width of the $\beta$-Ti layer was diffusion controlled. The growth of the diffusion layer can be assumed to follow a parabolic law. Growth of the interlayer thickness can be denoted by the following relations $[60,64]$ :

$$
\begin{aligned}
x^{2} & =k t, \\
k & =k_{0} e^{-(\mathrm{Q} / R T)},
\end{aligned}
$$

where $x$ is the thickness of the reaction layer $(\mathrm{m}), t$ is the bonding time (s), $T$ is the bonding temperature $(\mathrm{K}), k$ is the growth velocity of the reacting layer $\left(\mathrm{m}^{2} / \mathrm{s}\right), k_{0}$ is the growth constant $\left(\mathrm{m}^{2} / \mathrm{s}\right), Q$ is the activation energy for the layer growth $(\mathrm{kJ} / \mathrm{mol})$, and $R$ is the real gas constant $(8.314 \mathrm{~J} / \mathrm{K} \mathrm{mol})$.

According to the experiment results (the relationship between the thickness of the reaction layer and bonding 


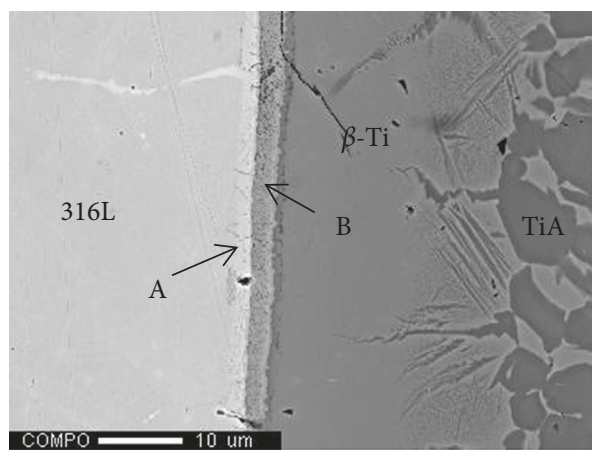

(a)

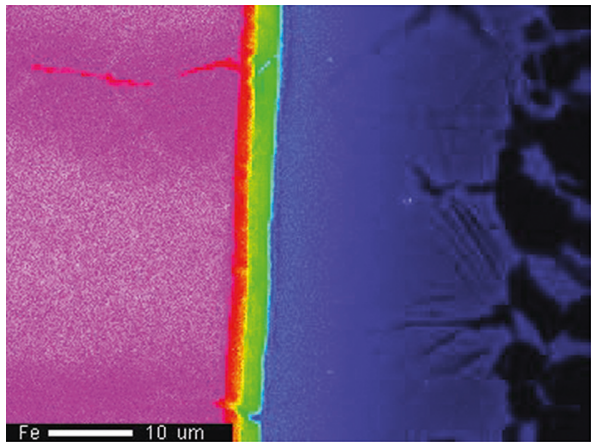

(c)

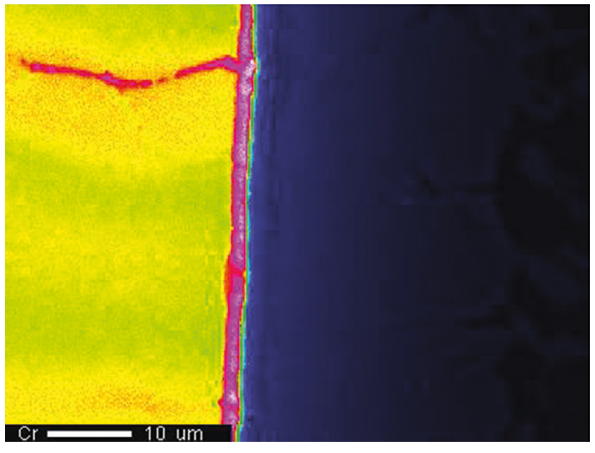

(e)

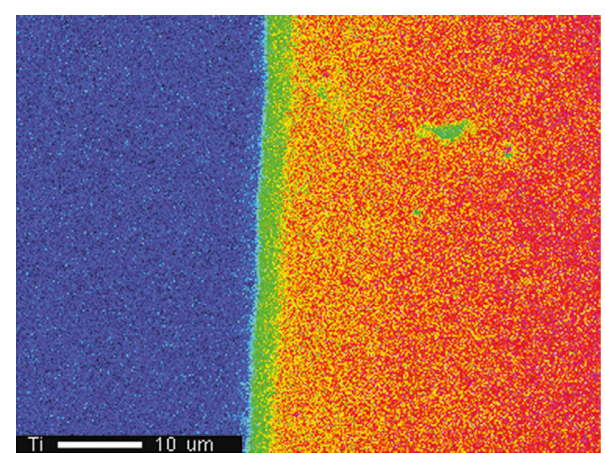

(b)

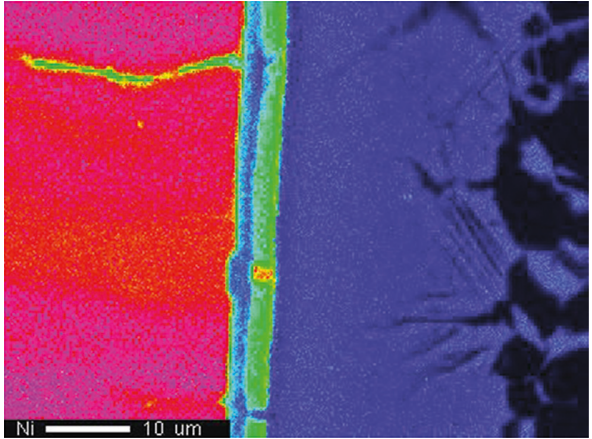

(d)

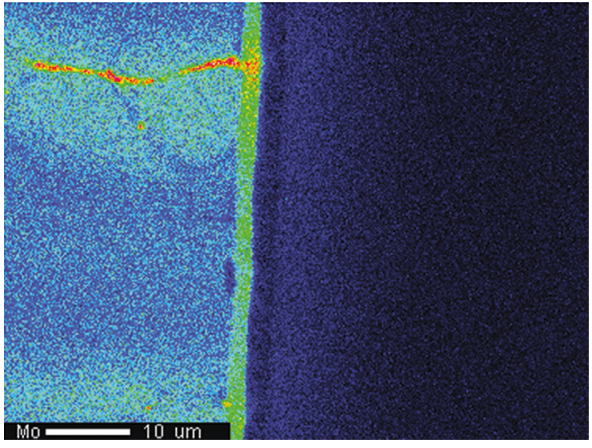

(f)

FIgURE 2: Concentration profiles from EPMA analysis of elements Ti, Fe, Ni, Cr, and Mo along with a BSE image of a region at Ti-6Al-4V and 316L stainless steel joint interface bonded at $900^{\circ} \mathrm{C}$ : (a) BSE image; (b) Ti map; (c) Fe map; (d) Ni map; (e) Cr map; (f) Mo map.

temperature), some reaction layers' growth kinetics are listed in Table 1. It can be found that calculated activation energies of $\alpha-\mathrm{Fe}+\lambda$ and $\beta$-Ti are divergent in the literatures. The reason for this phenomenon is that the detection of the thickness of the reaction layer is different from each other, and elevated rate and cooling rate of furnace also have influence on the calculated results. Miriyev et al. [65] investigated growth kinetics of the $\mathrm{TiC}$ interfacial layer formed in the diffusion bonding of low-alloy carbon steel ( $0.3 \mathrm{wt} . \%$ C) and $\mathrm{Ti}$ alloy, which was dominated by diffusion of carbon atoms from steel side to titanium alloy side through the TiC phase. When the thickness of the TiC layer is less than $1 \mu \mathrm{m}$, the carbon diffusion in austenite is at a rate-determining step. Growth kinetics of interface layers can be utilized to control the width and microstructure of the interfacial reaction layer which is benefit for the improvement of mechanical property of bonded joints. However, optimizing the accuracy of activation energy needs further investigation.

At present, growth kinetics of interfacial phases are calculated by the simplified model. Namely, diffusion in single-phase solid solution where no interphase exists. However, in fact, many new phases are formed at the interface between titanium alloy and stainless steel during diffusion bonding. This means that the process is reaction diffusion. Diffusion coefficients and activation energy confirmed from the simplified model are inaccurate for predicting the microstructures of the joints. According to kinetic analysis, the growth velocity of the reacting layer can be obtained from the experimental results, while the change of the microstructure at the interface is unknown. Therefore, moving speed of phase interface and the order for a new phase that appears also need to be further investigated. 


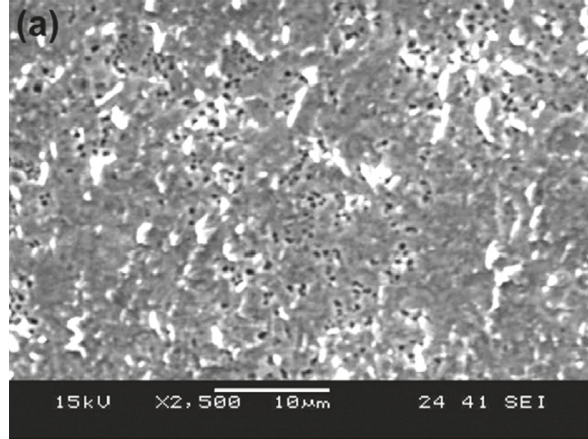

(a)

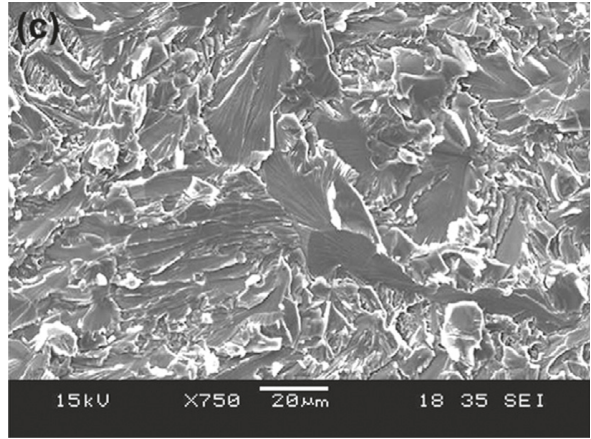

(c)

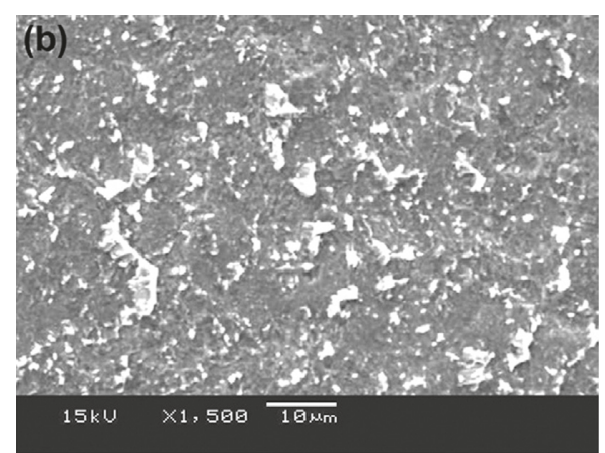

(b)

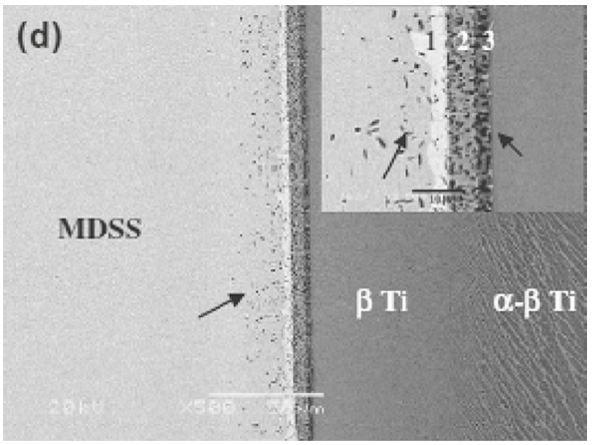

(d)

FIgURE 3: Fracture morphology of the bonded joints at (a) $850^{\circ} \mathrm{C}$; (b) $900^{\circ} \mathrm{C}$; (c) $950^{\circ} \mathrm{C}$ for 45 min at stainless steel side; (d) BSE micrographs of the diffusion-bonded sample at $1000^{\circ} \mathrm{C}$ for $45 \mathrm{~min}$ and enlarge view at inset: (1) $\sigma$; (2) $\lambda+\mathrm{FeTi}$; and (3) $\lambda+\mathrm{FeTi}+\beta-\mathrm{Ti}$ (the arrows show the microvoids) (reproduced from [64] with permission).

TABLE 1: Growth kinetics of the reaction layers.

\begin{tabular}{lc}
\hline Interface layers & Activation energy, $Q(\mathrm{~kJ} / \mathrm{mol})$ \\
\hline$\alpha-\mathrm{Fe}+\lambda$ & $209.9[64], 124.9[65]$ \\
$\beta-\mathrm{Ti}$ & $122.1[64], 133.7[65]$ \\
$\chi$ & $80.8[64]$ \\
$\mathrm{Fe}_{2} \mathrm{Ti}$ & $39.9[64]$ \\
\hline
\end{tabular}

\section{Diffusion Bonded Joints with Interlayer}

Apart from optimizing the parameters for diffusion bonding between dissimilar materials, the interlayer is often employed to control the microstructure of joints, especially declining the content of brittle phases at the interface. Simoes et al. [66] adopted Ni/Al nanolayers as an interlayer to join TiAl and AISI 310 stainless steel. $\mathrm{Ti}_{3} \mathrm{Al}$, $\mathrm{FeAl}, \mathrm{FeAl}_{2}$, and $\sigma$ phases disappeared, and the values of shear strength of joint rose fourfold compared to the joints made without the interlayer. He et al. [67] conducted the composite barrier layer of $\mathrm{Ti} / \mathrm{V} / \mathrm{Cu}$ as the interlayer to join $\mathrm{TiAl}$ and steel. The interface was composed of $\mathrm{Ti}_{3} \mathrm{Al}+\mathrm{TiAl}$ and $\mathrm{Ti}$ solid solutions at TiAl side, and a sound joint was obtained. Only solid solution was formed at the Mo-Ni and $\mathrm{Ni}-\mathrm{Cu}$ interfaces when a $\mathrm{Ni}$ interlayer was included to diffusion bond $\mathrm{Mo} / \mathrm{Cu}$ joints [68]. Applying $\mathrm{Ag}-\mathrm{Cu}$-Ti filler to join WC-Co and Ti-6Al-4V, wettability of the interfaces could be improved [69].
Selection of the interlayer is based on two points which are relevant to overcome the restrictions of achieving highquality joints. On the one hand, the interlayer is benefit for changing the microstructure of interface into less brittle phases. On the other hand, the expansion coefficient of the interlayer is between titanium alloy and stainless steel, and the interlayer is with good plasticity for releasing welding stress at the joints. When bonding titanium alloy and stainless steel, $\mathrm{Cu}, \mathrm{Ni}, \mathrm{Ag}, \mathrm{V}$, and $\mathrm{Nb}$ are often composed as the interlayer to restrain diffusion of Fe atom into titanium alloy side and reduce or remove the formation of FeTi and Fe-Cr-Ti phases.

3.1. Cu Interlayer. Figure 4 shows the backscattered electron image of titanium alloy and stainless steel joined at $900^{\circ} \mathrm{C}$ for 60 min with $\mathrm{Cu}$ as the interlayer. It can be seen that a few of $\lambda, \chi$, and FeTi phases formed at stainless steel-Cu side, and the interface is dominated by $\mathrm{Cu}_{3} \mathrm{Ti}_{2}+\mathrm{Cu}_{4} \mathrm{Ti}+\mathrm{Ti}-\mathrm{Cu}-\mathrm{Fe}$ phases. Due to the effect of $\mathrm{Cu}$, a kind of the $\beta$-Ti stabling phase, $\alpha-\beta \mathrm{Ti}$ is presented at $\mathrm{Ti}$ side. A maximum tensile strength of $\sim 322 \mathrm{MPa}$ with a ductility of $\sim 8.5 \%$ has been obtained [35].

According to the CuTi phase diagram, from 890 to $960^{\circ} \mathrm{C}$, two eutectic transformations exist, which makes it possible to introduce a small amount of the liquid phase at the CuTi joints when a suitable bonding temperature is selected. Based on this principle, the transient liquid-phase (TLP) bonding is conducted to join titanium alloy and stainless steel. To 


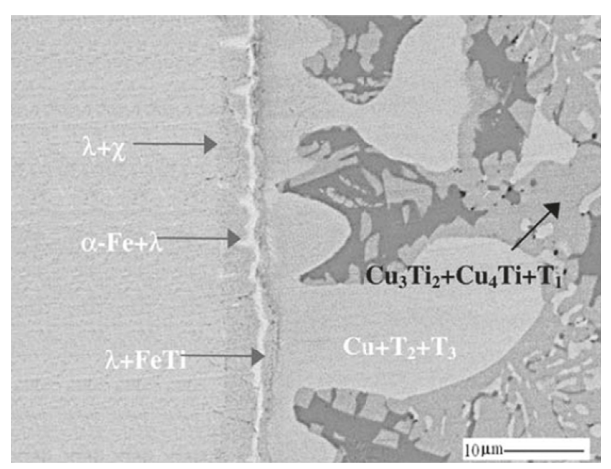

(a)

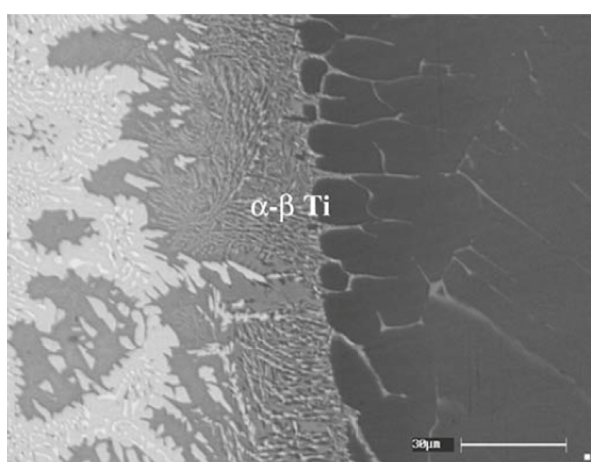

(b)

Figure 4: BSE image of the specimen processed for $60 \mathrm{~min}$ at (a) $900^{\circ} \mathrm{C}$, SS-Cu interface and (b) $900^{\circ} \mathrm{C}$, CuTi interface (reproduced from [35] with permission).

perform TLP bonding, the $\mathrm{Cu}$ interlayer is placed between titanium alloy and stainless steel, and the components are heated at setting temperature which is usually near the temperature of eutectic transformation $[36,70]$.

Norouzi et al. [71] investigated the influence of bonding temperature $\left(870-960^{\circ} \mathrm{C}\right)$ on the transient liquid-phase bonded joints of Ti-6Al-4V to AISI 304 austenitic stainless steel. When bonding temperature reached up to $960^{\circ} \mathrm{C}$, eutectic and intermetallic zones were completely eliminated on account of more solid-state diffusion of $\mathrm{Cu}$ into Ti-6Al-4V which demonstrated that complete isothermal solidification was achieved. Fracture morphology of joints fabricated at $960^{\circ} \mathrm{C}$ revealed a brittle-ductile fracture mode. Figure 5 shows the SEM (scanning electron microscopy) images and EBSD (electron backscattered diffraction) analysis of joint bonded at $900^{\circ} \mathrm{C}$ for $40 \mathrm{~min}$. It is illustrated that a number of compounds, such as $\mathrm{Ti}_{2} \mathrm{Cu}, \mathrm{TiCu}, \mathrm{FeTi}$, and $\mathrm{Fe}_{2} \mathrm{Ti}$, were formed at the joints. $\mathrm{Ti}_{2} \mathrm{Cu}$ with $\alpha$-Ti was produced by eutectoid reaction $\beta-\mathrm{Ti} \leftrightarrow \alpha-\mathrm{Ti}+\mathrm{Ti}_{2} \mathrm{Cu}$. The content of the TiFe phase is less than that of the CuTi phase, which is due to the fact that the diffusion rate of $\mathrm{Ti}$ in $\mathrm{Cu}$ is higher than that of $\mathrm{Fe}$ in $\mathrm{Cu}$, thus declining the brittleness of joints [72]. Norouzi et al. [73] also studied the effect of bonding time on the property of the transient liquid-phase bonded joints with copper as the interlayer. The time required for complete isothermal solidification can be calculated by $[71,74]$

$$
t_{\mathrm{IS}}=\frac{W_{\max }^{2}}{16 K^{2} D},
$$

where $W_{\max }$ is the maximum liquid width proportional to the initial interlayer thickness, $K$ is a constant, and $D$ is the solute diffusivity in the base metal. As the bonding time increases to $60 \mathrm{~min}$, the amount of the intermetallic compound was decreased and only single-phase solid solution $\beta$-Ti existed at the interface, which gives rise to a maximum shear strength of $374 \mathrm{MPa}$ [73].

Zakipour et al. $[75,76]$ investigated the influence of $\mathrm{Cu}$ interlayer's thickness on diffusion bonding behavior of stainless steel $316 / \mathrm{Ti}-6 \mathrm{Al}-4 \mathrm{~V}$ system. $\mathrm{Ti}_{2} \mathrm{Cu}, \mathrm{TiCu}, \mathrm{Cr}_{2} \mathrm{Ti}$, $\mathrm{Fe}_{2} \mathrm{Ti}, \mathrm{Cu}_{0.8} \mathrm{Fe}_{0.2} \mathrm{Ti}, \mathrm{Fe}_{4} \mathrm{Cu}_{3}$, and $\mathrm{TiCu}_{2}$ were identified at the interface. With the increase of $\mathrm{Cu}$ interlayer thickness, the shear strength value that decreased gradually attributed to distribution of more brittle intermetallic compounds at the joint. The maximum shear strength of $220 \mathrm{MPa}$ was obtained for the joint bonded at $900^{\circ} \mathrm{C}$ with $50 \mu \mathrm{m}$ thick interlayer.

3.2. Ni Interlayer. Yildiz et al. [77] used nickel as the interlayer to bond titanium and ferritic stainless steel, and due to the diffusion of atoms, different intercomposites occurred in titanium-nickel and ferritic stainless steel-nickel side. At titanium-nickel side, NiTi and FeTi phases were formed, while $\mathrm{Ni}-\mathrm{Cr}$ and Fe-Ni phases were formed at ferritic stainless steelnickel side. In terms of intermetallic formation in the joint, the maximum tensile strength is only $214 \mathrm{MPa}$. Szwed and Konieczny [78] performed diffusion brazing to join titanium and stainless steel using a nickel foil as a transit layer. Eutectoid mixture $\alpha-\mathrm{Ti}+\mathrm{Ti}_{2} \mathrm{Ni}$ and layers of intermetallic phases $\mathrm{Ti}_{2} \mathrm{Ni}, \mathrm{TiNi}$, and $\mathrm{TiNi}_{3}$ composed titanium side. When the bonding temperature was lower than $850^{\circ} \mathrm{C}$, no reaction layer appeared at stainless steel-nickel side.

Sam et al. [79] used $150 \mu \mathrm{m}$ thick nickel alloy (NiA, Ni 78.76 wt.\%, Fe 15.6 wt.\%, Mo 4.9 wt.\%, and $\mathrm{Al} 0.74$ wt.\%) as the interlayer to accomplish diffusion bonding of titanium alloy and microduplex stainless steel (MDSS). Microstructure of joints bonded at $900^{\circ} \mathrm{C}$ for $45 \mathrm{~min}$ is shown in Figure 6. It can be seen that at MDSS-NiA side (Figure 6(a)), no intermetallic phases are formed. From the enlarged picture in Figure $6(\mathrm{~b}), \mathrm{Ni}_{3} \mathrm{Ti}, \mathrm{NiTi}$, and $\mathrm{NiTi}_{2}$ phases are presented at layer A to $\mathrm{C}$, respectively. These phases possess relatively lower hardness of $\sim 662 \mathrm{HV}$ than that of $\mathrm{FeTi}$ phases ( $950 \mathrm{HV})$. Maximum tensile strength reaches up to $~ 560 \mathrm{MPa}$. Kundu et al. [80] experimented a kind of nickel alloy (Ni 74.7 wt.\%, Fe 8.6 wt.\%, and Cr 16.7 wt.\%) as the interlayer. When the bonding time was beyond $30 \mathrm{~min}$ and bonding temperature was higher than $900^{\circ} \mathrm{C}, \sigma, \chi$ and $\lambda+\mathrm{Fe}_{2} \mathrm{Ti}$ phases were appeared at stainless steel-NiA side, which was detrimental to the quality of the joints.

Impulse diffusion bonding is a technology developed by the Ukraine Barton Welding Institute firstly. According to material contact strength theory and the relationship between loading rate and the diffusion ability of materials, diffusion bonding is established to join materials with the interlayer by a changing pressure [81]. Impulsive loading is propitious to restrict and break the oxide film and brittle phases at the 

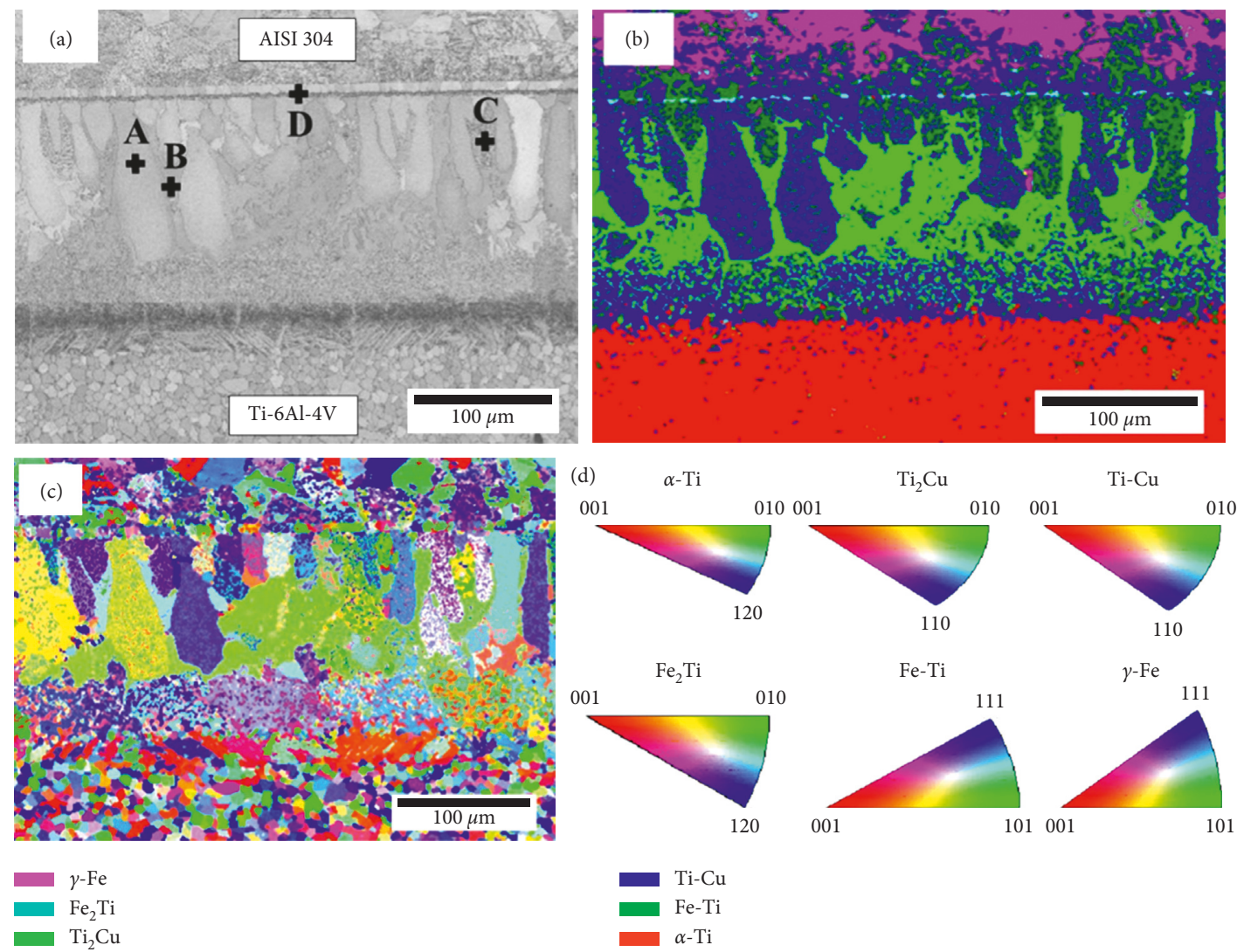

FIGURE 5: SEM micrographs and EBSD analysis of the sample bonded for 40 min at $900^{\circ} \mathrm{C}$ : (a) SEM micrographs; (b) phase map; (c) inverse pole figure; (d) legend of inverse pole figure (reproduced from [72] with permission).
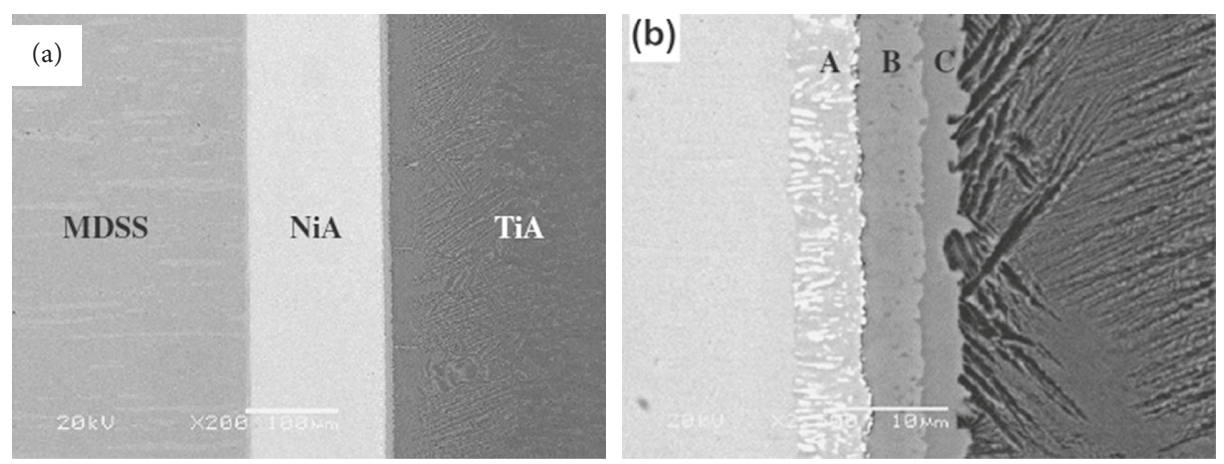

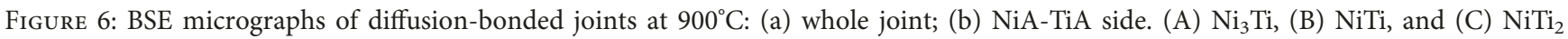
(reproduced from [79] with permission).

interface effectively. Therefore, the bonding strength of joints can be possibly improved by applying this technique. Wang et al. [82] used a pure Ni interlayer to bond pure titanium and 304 stainless steel by impulse pressuring diffusion bonding technology. Bonding pressure was 8-20 MPa under a uniaxial load for $60-150 \mathrm{~s}$ in vacuum. $\mathrm{Ti}_{2} \mathrm{Ni}, \mathrm{TiNi}$, and $\mathrm{TiNi}_{3}$ were formed at the joints, and the optimized tensile strength value of $\sim 358 \mathrm{MPa}$ can be achieved for a bonding time of $90 \mathrm{~s}$.

3.3. Ag Interlayer. Deng et al. [83] used Ag as the interlayer to achieve diffusion bonding of titanium to 304 stainless steel and investigated the influence of temperature on the strength of joints. The results showed that TiAg compound was formed at TiAg interface whose hardness was $96 \mathrm{HV}$, which can accomplish a plastic transition. When exposed to tensile strength, a bonding strength of $\sim 400 \mathrm{MPa}$ could be obtained at $825-875^{\circ} \mathrm{C}$ for $20 \mathrm{~min}$, and the joints were ductile in nature. BSE image and corresponding line scanning of the joint bonded at $850^{\circ} \mathrm{C}$ for $20 \mathrm{~min}$ are presented in Figure 7, and it can be concluded that the joints were composed of stainless steel (SS)/Ag/TiAg/Ti solid solute (s.s)/Ti.

Balasubramanian [84] applied the Box-Behnken design for titanium-steel joints with the silver interlayer by diffusion bonding and investigated the sensitivity of joints' properties to bonding temperatures, holding times, and 
bonding load. The results confirmed the function of the Ag interlayer to prevent the diffusion between $\mathrm{Ti}$ and $\mathrm{Fe}$ or $\mathrm{C}$. Sensitivity analysis showed that the responses were not sensitive to any small changes in bonding temperatures, holding times, and bonding load, which is in agreement with the results of the former literature [83]. The formation of TiAg attributed to the increase of bonding strength, and adequate ductility of $18 \%$ could be obtained.

Comparatively, the Ag interlayer is the only single interlayer that eliminates the brittle phase at the interface among $\mathrm{Cu}, \mathrm{Ni}$ or nickel alloy, and Ag. The formation of TiAg phase between $\mathrm{Ag}$ and titanium alloy is benefit for the joining between them. Optimized strength of the joint can reach up to $400 \mathrm{MPa}$ when bonding at $825-875^{\circ} \mathrm{C}$ for $20 \mathrm{~min}$ with the thickness of $50 \mu \mathrm{m}$ and fracture nature of the joint is ductile. It can be concluded that the $\mathrm{Cu}$ interlayer can decline the content of FeTi and $\mathrm{Fe}-\mathrm{Cr}$-Ti phases at the interface dramatically by forming $\mathrm{TiCu}$ phases. At the same time, lower hardness of the joint is obtained and the brittleness of the joint is decreased. According to the CuTi phase diagram, a small amount of the liquid phase at the CuTi joints can be introduced by bonding at 890 to $960^{\circ} \mathrm{C}$. The liquid phase can shrink the time used for diffusion bonding significantly, which favors improving the efficiency of bonding process. The usage of the nickel alloy interlayer for diffusion bonding between titanium alloy and stainless steel achieved the highest tensile strength of $\sim 560 \mathrm{MPa}$. $\mathrm{Ni}_{3} \mathrm{Ti}, \mathrm{NiTi}$, and $\mathrm{NiTi}_{2}$ phases formed sequentially at nickel alloy and titanium alloy side with a holding time of $45 \mathrm{~min}$ at $900^{\circ} \mathrm{C}$.

3.4. Multi-Interlayer. It should be noticed that the single interlayers mentioned above can still form intermetallic compounds with one of the parent metals, which makes it difficult to achieve high-quality joints, especially the usage of $\mathrm{Cu}$ and $\mathrm{Ni}$ that makes the brittle phase to exist at the joints. Insertion of a multi-interlayer has been considered as a potential approach to prevent or reduce the formation of undesired intermetallic compounds in joints.

Kundu et al. [85] used $\mathrm{Ni}$ and $\mathrm{Cu}$ as composite intermediate metals to join duplex stainless steel and Ti-6Al$4 \mathrm{~V}$. At $\mathrm{Cu}$ and $\mathrm{Ti}$ alloy interface, $\mathrm{Cu}_{4} \mathrm{Ti}, \mathrm{Cu}_{2} \mathrm{Ti}, \mathrm{Cu}_{4} \mathrm{Ti}_{3}, \mathrm{CuTi}$, and $\mathrm{CuTi}_{2}$ phases were formed. At the stainless steel side and $\mathrm{Ni}-\mathrm{Cu}$ interface, no intermetallic phases were observed. Fracture took place at $\mathrm{Cu}_{4} \mathrm{Ti}$ intermetallic, $\mathrm{Ni}_{3} \mathrm{Ti}$, and $\sigma$ phases with bonding temperature increasing, and a maximum shear strength of 377.4 MPa can be obtained. Lee et al. [86] considered vanadium as an interlayer for dissimilar bonding of titanium to stainless steel at $900^{\circ} \mathrm{C}$ for $10 \mathrm{~min}$. Ti$\mathrm{V}$ solid solution was formed at $\mathrm{Ti}$ side, and $\mathrm{Ti}_{2} \mathrm{Ni},(\mathrm{Ti}, \mathrm{Zr})_{2} \mathrm{Ni}$, and brittle $\sigma$ phases were easily segregated in the vicinity of the $\mathrm{V}$ layer because of an incomplete isothermal solidification. When using $\mathrm{Cr}-\mathrm{V}$ multi-interlayer, the thickness of the brittle $\sigma$ phase was suppressed. To eliminate such brittle $\sigma$ phases, the Ni-Cr-V interlayer was utilized, which produced a no brittle intermetallic joints comprising $\mathrm{Ti} / \alpha+\beta \mathrm{Ti} / \beta$ $\mathrm{Ti} / \mathrm{V} / \mathrm{Cr} / \mathrm{Ni} /$ stainless steel. The Ni-Cr-V interlayer made the bonding strengths of the joints to exceed the strength of the base metal of Ti. Li et al. [87] conducted diffusion bonding of titanium to austenitic stainless steel using $\mathrm{Nb} / \mathrm{Cu} / \mathrm{Ni}$ structure as the multi-interlayer. The aggregation of $\mathrm{Ni}$ atoms promoted a solution of $\mathrm{Cu}$ into $\mathrm{Nb}$, but the brittle $\mathrm{Nb}-\mathrm{Ni}$ phase tended to form at the interface when using long bonding times or high bonding temperature. Bonding strength around $300 \mathrm{MPa}$ could be obtained with a ductile dominated fracture surface which contained some terraces and pits.

Figure 8 shows EPMA line scanning analysis of elements $\mathrm{Ti}, \mathrm{Fe}, \mathrm{Cu}, \mathrm{Ni}, \mathrm{Cr}$, and $\mathrm{Nb}$ along with a BSE image of a region at Ti-6Al-4V and $316 \mathrm{~L}$ joint interface bonded at $900^{\circ} \mathrm{C}$ with $\mathrm{Cu} / \mathrm{Nb}$ multi-interlayer. It is obvious that $\mathrm{Cu} / \mathrm{Nb}$ multiinterlayer prevents the formation of TiFe brittle phases at the interface effectively and no intermetallic compounds are presented at TiA side. At TiA-Nb side, Ti-Nb solid solution ( $\alpha-\beta \mathrm{Ti})$ was formed. Owing to the low diffusivity and solubility between $\mathrm{Nb}$ and $\mathrm{Cu}$, the diffusion layer between $\mathrm{Nb}$ and $\mathrm{Cu}$ is not apparent.

Figure 9 represents distribution of elements $\mathrm{Ti}, \mathrm{Nb}, \mathrm{Cu}$, $\mathrm{Ni}, \mathrm{Cr}$, and $\mathrm{Fe}$ along with a BSE image of a region at Ti-6Al-4V and $316 \mathrm{~L}$ joint interface bonded at $950^{\circ} \mathrm{C}$. At the adjacent of TiA side, dendritic area is indicated in Figure 9(a). Based on the element distribution in Figures 9(b)-9(f), it is deduced to be $\mathrm{Ti}_{2} \mathrm{Cu}+\alpha-\beta \mathrm{Ti}$ phase that is formed by the eutectoid reaction $\left(\beta-\mathrm{Ti} \leftrightarrow \mathrm{Ti}_{2} \mathrm{Cu}+\alpha-\mathrm{Ti}\right)$ at the temperature of $790^{\circ} \mathrm{C}$ [88]. $\mathrm{Cu}$ and $\mathrm{Nb}$ are $\beta$-stabilizing element to titanium alloy, which results in high-temperature $\beta$ phase to retain at room temperature. Island area A is mainly composed of $\mathrm{Ti}$ (52.50 at.\%), and $\mathrm{Cu}$ (29.24 at.\%) and possible phases of area $\mathrm{A}$ are $\mathrm{Ti}_{2} \mathrm{Cu}$ dissolved with little $\mathrm{Fe}$ and $\mathrm{Nb}$ atoms. Comparatively, the area $\mathrm{B}$ surrounding the island area A contents more $\mathrm{Cu}$. According to the EDS result and phase diagram [89], area B is presumably the phase of Ti-Cu dissolved with little Fe atom. Area $\mathrm{C}$ is near the stainless steel, and $\mathrm{Fe}, \mathrm{Ni}, \mathrm{Cr}$, and little $\mathrm{Ti}$ are aggregated at this area which is possible to be the brittle FeCr-Ti phase that is the most vulnerable part of the joint [90]. Close to remnant $\mathrm{Nb}$ side is mainly comprised of $\mathrm{Nb}$ solid solution. Due to the formation of these phases, the strength of joints bonded at $950^{\circ} \mathrm{C}$ is dramatically declined compared to that bonded at $900^{\circ} \mathrm{C}$.

Generally, the selection of multi-interlayer was also based on two principles: no brittle intermetallic phases are formed at the interface of multi-interlayer and parent metals. Physical properties of the multi-interlayer should be good for the transition between titanium alloy and stainless steel, such as good plasticity for releasing thermal stress and thermal expansion coefficient between that of parent metal. Compared with $\mathrm{Cu} / \mathrm{Ni}$ multi-interlayer, application of $\mathrm{Ni} / \mathrm{Cr} / \mathrm{V}, \mathrm{Nb} / \mathrm{Cu} / \mathrm{Ni}$, and $\mathrm{Cu} / \mathrm{Nb}$ multi-interlayer well prevents the formation of intermetallic phases, and the strength of the joints is improved. However, controlling of the parameters, such as bonding temperature and bonding time, has a great effect on the microstructure and strength of the joints welded with multi-interlayer. Bonding temperature is usually restricted at $800-950^{\circ} \mathrm{C}$ for the bonding with the interlayer, and if $\mathrm{Cu}$ is used as the interlayer, the eutectic liquid phase should be avoided by adjusting the bonding temperature. Due to the formation of solid solution at the interface, the parabolic diffusion law can be employed to predict the suitable parameters for diffusion bonding. 

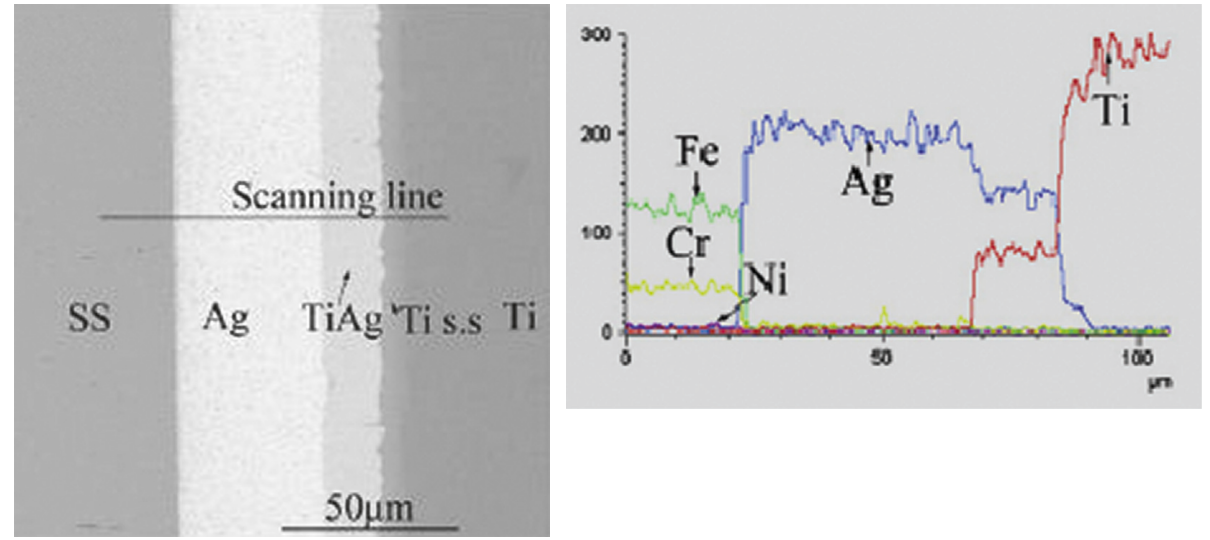

FIGURE 7: BSE image and corresponding line scanning of the joint bonded at $850^{\circ} \mathrm{C}$ for 20 min (reproduced from [83] with permission).
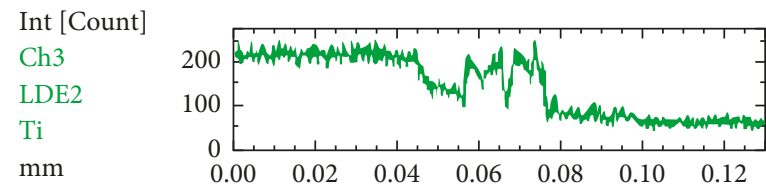

(a)

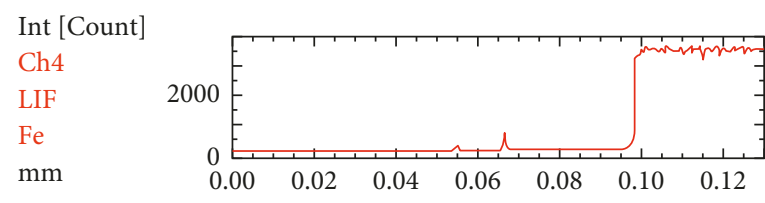

(c)

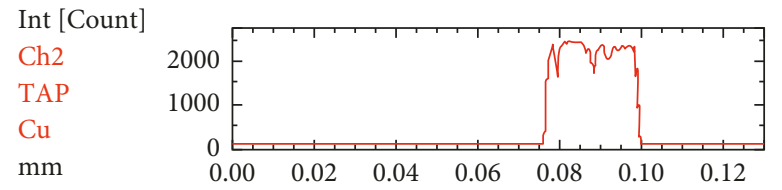

(e)

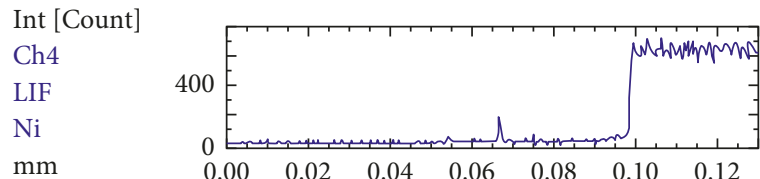

(b)

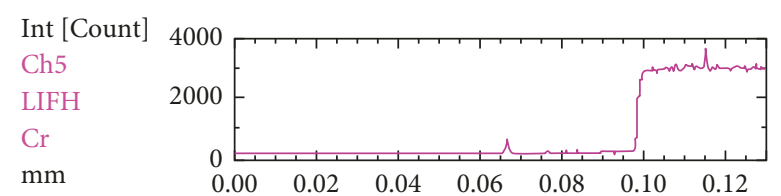

(d)

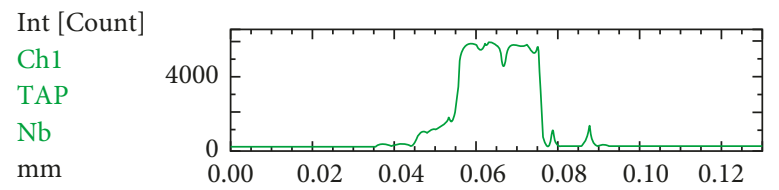

(f)

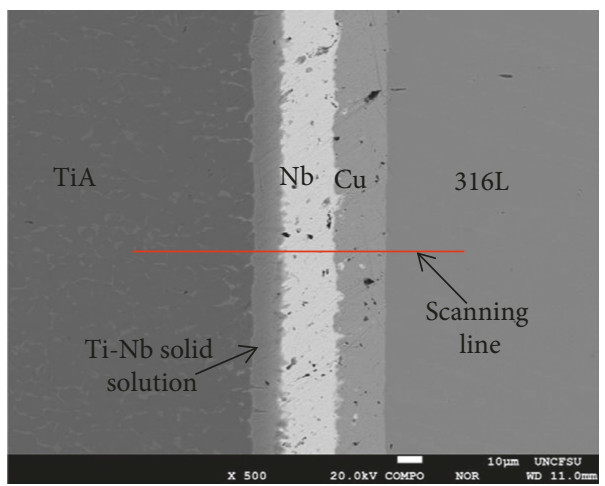

(g)

Figure 8: EPMA line scanning analysis of elements (a) Ti, (b) Fe, (c) $\mathrm{Cu}$, (d) Ni, (e) Cr, and (f) Nb along with (g) a BSE image of a region at Ti-6Al-4V and $316 \mathrm{~L}$ joint interface bonded at $900^{\circ} \mathrm{C}$.

\section{Mechanism of Diffusion-Bonded Joints}

The process of diffusion boding without the interlayer can be summarized as follow: the first stage is the matching surface closure by diffusion of atoms at certain temperature and reaction products formed promote the joining of bimetallic structures. The second stage is the formation of brittle intermetallic compounds, and the width of them governs the strength of joints. Due to the Kirkendall effect, the third stage is the formation of voids near the interface region, which further diminishes the mechanical property. 


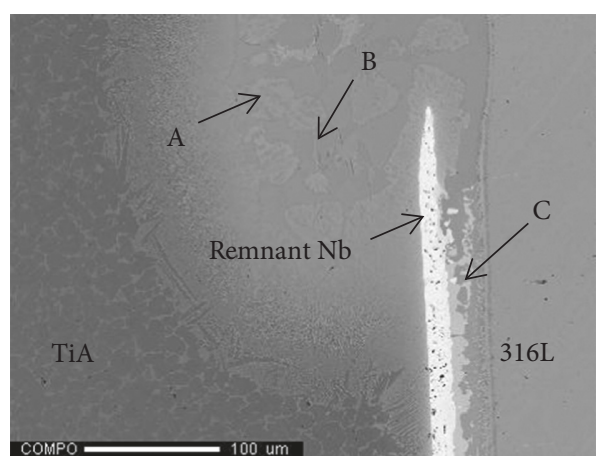

(a)

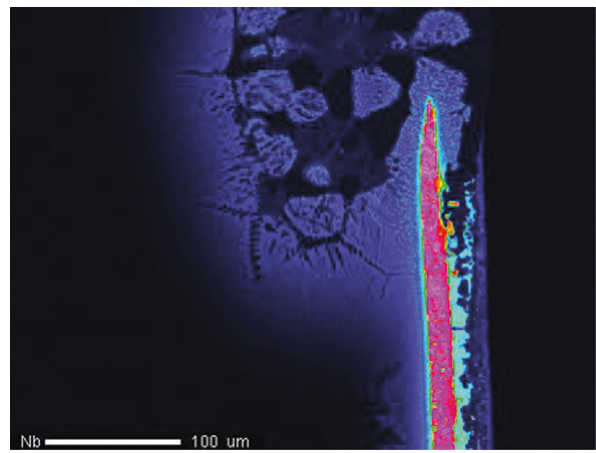

(c)

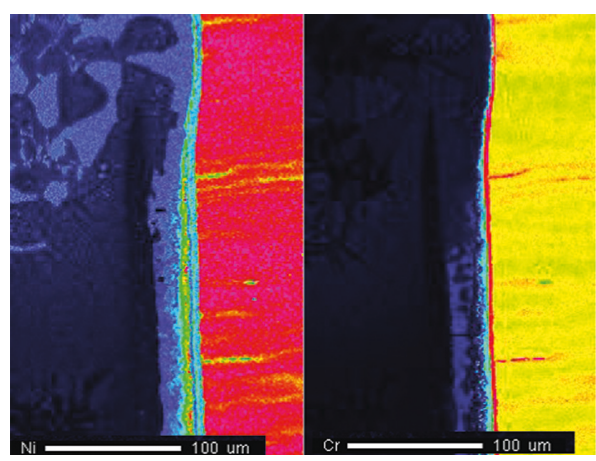

(e)

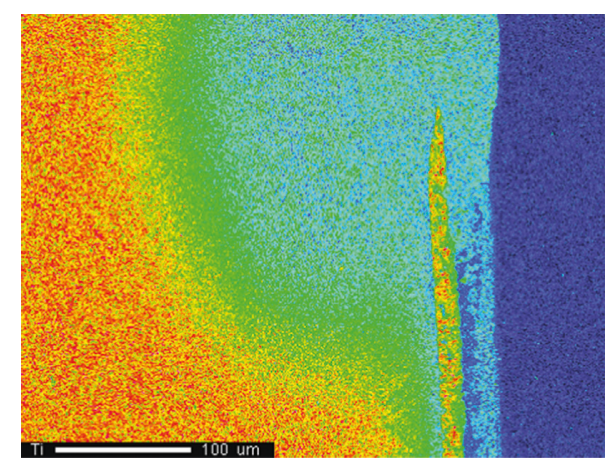

(b)

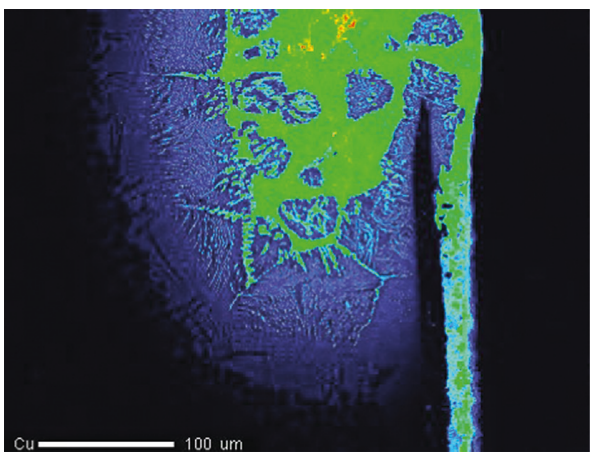

(d)

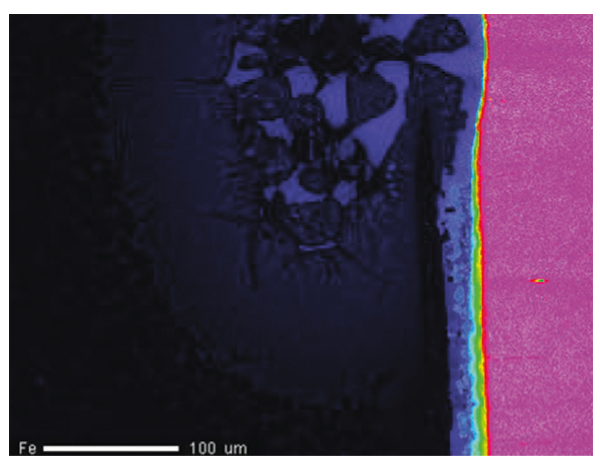

(f)

Figure 9: Concentration profiles from EPMA analysis of elements Ti, Nb, Cu, Ni, Cr, and Fe along with a BSE image of a region at Ti-6Al-4V and 316L joint interface bonded at $950^{\circ} \mathrm{C}$ : (a) BSE image; (b) Ti map; (c) Nb map; (d) Cu map; (e) Ni and Cr map; (f) Fe map.

Figure 10 presents the formation process of titanium alloy and stainless steel diffusion-bonded joint using $\mathrm{Cu} / \mathrm{Nb}$ multi-interlayer. When the interlayer is inserted between titanium alloy and stainless steel, the first stage is the same as that of the joint bonded without the interlayer, as shown in Figures 10(a)-10(b). Pores are gradually closed by diffusion of atoms and growth of grains, and then diffusion layers are formed at the interfaces. The second stage is that the thickness of $\alpha-\beta \mathrm{Ti}$ and diffusion layers increases with the expansion of bonding time, which promotes the joining of each interface, as shown in Figure 10 (c). At the third stage, due to the aggregation of $\mathrm{Ti}$ atoms at $\mathrm{Nb}-\mathrm{Cu}$ interface, the eutectic liquid phase can be introduced into this area that results in the diffusion and dissolution of $\mathrm{Nb}$ foil which undermines barrier effect of the $\mathrm{Nb}$ layer and further contributes to the formation of intermetallic compounds at the interface and TiA side, as shown in Figures 10(d)-10(e).

When using Ag as the interlayer [83], brittle intermetallic phases were diminished at the interface. TiAg and Ti-based solid solution formed at the second stage strengthened the joint. Lee et al. [86] considered $\mathrm{Ni}-\mathrm{Cr}-\mathrm{V}$ as the multiinterlayer which produced a no brittle intermetallic joints comprising $\mathrm{Ti} / \alpha+\beta \mathrm{Ti} / \beta \mathrm{Ti} / \mathrm{V} / \mathrm{Cr} / \mathrm{Ni} /$ stainless steel. Li et al. [87] conducted diffusion bonding of titanium to austenitic stainless steel using $\mathrm{Nb} / \mathrm{Cu} / \mathrm{Ni}$ structure as multi-interlayer, optimized joint can be obtained at the second stage by the formation of the $\alpha-\beta \mathrm{Ti}$ phase at Ti-Nb interface. In conclusion, the presence of the transitional phases, such as TiAg and $\alpha-\beta \mathrm{Ti}$ at the second stage, prevents the formation of brittle intermetallic compounds and achieves ductile transition at the interface. The parameters should be controlled 


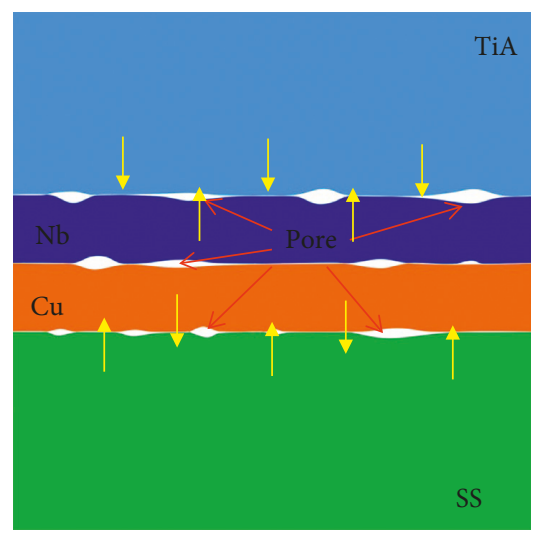

(a)

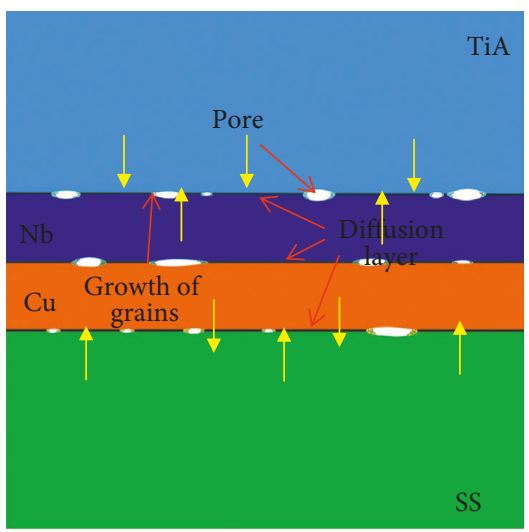

(b)

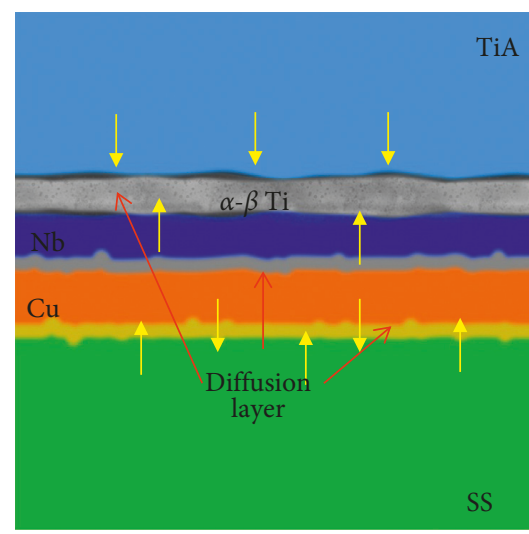

(c)

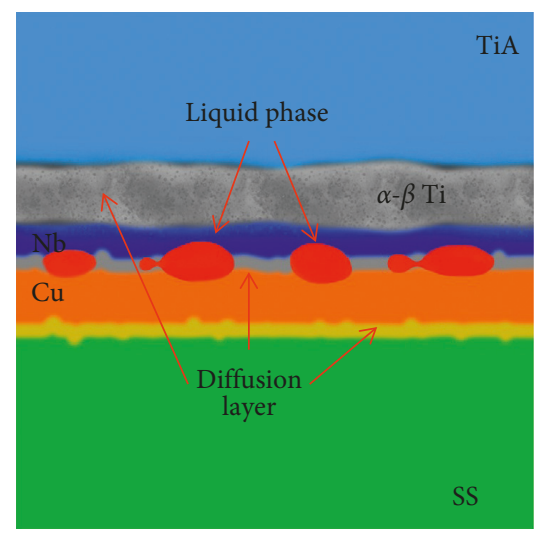

(d)

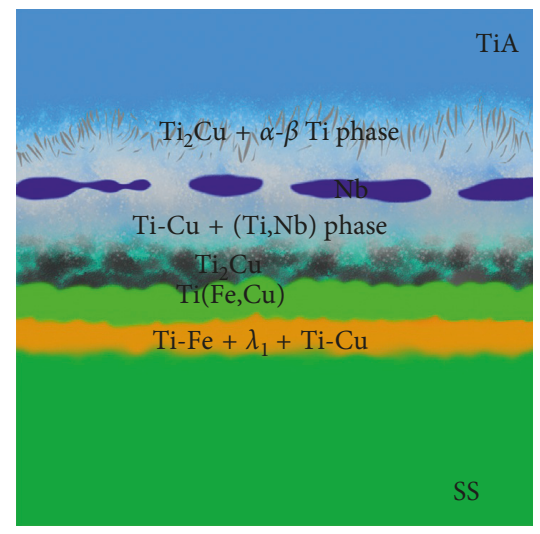

(e)

FIGURE 10: Formation process of titanium alloy and stainless steel diffusion-bonded joint using $\mathrm{Cu} / \mathrm{Nb}$ multi-interlayer: (a) pores exist at the interface; (b) diffusion of atoms and growth of grains; (c) formation of $\alpha-\beta$ Ti and diffusion layers; (d) liquid phase formed at the interface; (e) formation of intermetallic compounds.

according to kinetics of reaction diffusion so as to avoid the formation of brittle intermetallic compounds at the third stage.

\section{Conclusion}

This paper reviews recent efforts to study diffusion bonding between titanium alloy and stainless steel with and without interlayer. The microstructure of joints without interlayer and the growth kinetics of interfacial phases are compared. Optimized temperature for diffusion bonding of titanium alloy and stainless steel without the interlayer is in the range of $800-950^{\circ} \mathrm{C}$ for a time period of $60-120 \mathrm{~min}$. The sound joint can be obtained, but brittle FeTi and Fe-Cr-Ti phases formed at the interface. The development of joint mainly includes three steps: matching surface closure, growth of brittle intermetallic compounds, and formation of the Kirkendall voids. Growth kinetics of interfacial phases still needs further investigation in terms of growth velocity of the reacting layer, moving speed of phase interface, and the order for a new phase appears.

The influence of $\mathrm{Cu}, \mathrm{Ni}$ or nickel alloy, and $\mathrm{Ag}$ interlayers on the microstructures and mechanical properties of the joints is systematically summarized. The content of $\mathrm{FeTi}$ and $\mathrm{Fe}-\mathrm{Cr}$-Ti phases at the interface can be declined significantly. By employing transient liquid-phase bonding and impulse diffusion bonding, bonding efficiency is advanced dramatically, while there is no significant effect on the mechanical properties of the joint. Application of multiinterlayer well prevents the formation of intermetallic phases by forming solid solution at the interface, and the strength of the joints is improved. The parameters can be predicted by using the parabolic diffusion law. The selection of multiinterlayer was based on two principles: no formation of brittle intermetallic phases and transitional physical properties between titanium alloy and stainless steel.

\section{Conflicts of Interest}

The authors declare that there are no conflicts of interest regarding the publication of this paper.

\section{Authors' Contributions}

De-feng Mo and Xiao-song Jiang designed the structure of the review manuscript. Charles Q. Luo, Machael D. Simpson, and Zhi-ping Luo conducted EPMA analysis at FSU. De-feng Mo wrote the review manuscript with Ting-feng Song and Yong-jian Fang, and the manuscript was finalized 
through contributions of all the authors. All the authors have given approval to the final version of the manuscript.

\section{Acknowledgments}

This work was supported by the Youth Innovation Promotion Association (Chinese Academy of Sciences), Sichuan Science and Technology Support Program (no. 2016FZ0079), National Natural Science Foundation of China (no. 51201143), China Postdoctoral Science Foundation (no. 2015M570794), and R\&D Projects Funding from the Research Council of Norway (no. 263875/H30). The work at FSU was supported by the U.S. NSF (Grant no. HRD 1436120), and the instrumentation at FSU was funded by DOD (Grant no. W911NF-09-1-0011).

\section{References}

[1] Z. M. Li, X. P. Yang, J. B. Zhang, and A. D. Shan, "Interfacial mechanical behavior and electrochemical corrosion characteristics of cold-sprayed and hot-rolled titanium/stainlesssteel couples," Advanced Engineering Materials, vol. 18, no. 7, pp. 1240-1249, 2016.

[2] I. Tomashchuk, D. Grevey, and P. Sallamand, "Dissimilar laser welding of AISI 316L stainless steel to Ti6-Al4-6V alloy via pure vanadium interlayer," Materials Science and Engineering A, vol. 622, pp. 37-45, 2015.

[3] K. Liu, Y. Li, and J. Wang, "Improving the interfacial microstructure evolution of Ti/stainless steel GTA welding joint by employing $\mathrm{Cu}$ filler metal," Advanced Manufacturing Processes, vol. 31, no. 16, pp. 2165-2173, 2016.

[4] Q. Chu, M. Zhang, J. Li, C. Yan, and Z. Qin, "Influence of vanadium filler on the properties of titanium and steel tig welded joints," Journal of Materials Processing Technology, vol. 240, pp. 293-304, 2016.

[5] W. Li, S. Karnati, C. Kriewall et al., "Fabrication and characterization of a functionally graded material from Ti-6Al-4V to SS316 by laser metal deposition," Additive Manufacturing, vol. 14, pp. 95-104, 2017.

[6] Y. Zhang, D. Q. Sun, X. Y. Gu, and H. M. Li, "A hybrid joint based on two kinds of bonding mechanisms for titanium alloy and stainless steel by pulsed laser welding," Materials Letters, vol. 185, pp. 152-155, 2016.

[7] X. Yue, P. He, J. C. Feng, J. H. Zhang, and F. Q. Zhu, "Microstructure and interfacial reactions of vacuum brazing titanium alloy to stainless steel using an AgCuTi filler metal," Materials Characterization, vol. 59, no. 12, pp. 1721-1727, 2008.

[8] H. Alejandro, M. Jorge, R. Ashley et al., "Joining of inconel 718 and 316 stainless steel using electron beam melting additive manufacturing technology," Materials and Design, vol. 94, no. 15 , pp. 17-27, 2016.

[9] J. Song, A. Kostka, M. Veehmayer, and D. Raabe, "Hierarchical microstructure of explosive joints: example of titanium to steel cladding," Materials Science and Engineering A, vol. 528, no. 6, pp. 2641-2647, 2011.

[10] N. N. Kumar, G. D. J. Ram, S. S. Bhattacharya, H. C. Dey, and S. K. Albert, "Spark plasma welding of austenitic stainless steel AISI 304L to commercially pure titanium," Transactions of the Indian Institute of Metals, vol. 68, no. 2, pp. 289-297, 2015.

[11] T. F. Song, X. S. Jiang, Z. Y. Shao et al., "Interfacial microstructure and mechanical properties of diffusion-bonded joints of titanium TC4 (Ti-6Al-4V) and Kovar (Fe-29Ni-
17Co) alloys," Journal of Iron and Steel Research, vol. 24, no. 10, pp. 1023-1031, 2017.

[12] M. Kaya, M. Kılıc, I. Kırık, E. M. Karakurt, and B. Gulenc, "Diffusion bonding between Ti-6Al-4V alloy and interstitial free steel," Materialwissenschaft Und Werkstofftechnik, vol. 48, no. 7, pp. 661-665, 2017.

[13] B. Shanmugarajan and G. Padmanabham, "Fusion welding studies using laser on Ti-SS dissimilar combination," Optics and Lasers in Engineering, vol. 50, no. 11, pp. 1621-1627, 2012.

[14] H. C. Dey, M. Ashfaq, A. K. Bhaduri, and K. P. Rao, "Joining of titanium to 304L stainless steel by friction welding," Journal of Materials Processing Tech, vol. 209, no. 18, pp. 5862-5870, 2009.

[15] A. Miriyev, A. Stern, E. Tuval, S. Kalabukhov, Z. Hooper, and N. Frage, "Titanium to steel joining by spark plasma sintering (SPS) technology," Journal of Materials Processing Technology, vol. 213, no. 2, pp. 161-166, 2013.

[16] M. K. Lee, J. J. Park, G. J. Lee et al., "Corrosion of Ti-STS dissimilar joints brazed by a $\mathrm{Ag}$ interlayer and $\mathrm{Ag}-\mathrm{Cu}-(\mathrm{Pd})$ alloy fillers," Journal of Nuclear Materials, vol. 409, no. 3, pp. 183-187, 2011.

[17] J. G. Lee and M. K. Lee, "Microstructure and mechanical behavior of a titanium-to-stainless steel dissimilar joint brazed with Ag-Cu alloy filler and an Ag interlayer," Materials Characterization, vol. 129, pp. 98-103, 2017.

[18] T. Chung, J. Kim, J. Bang, B. Rhee, and D. Nam, "Microstructures of brazing zone between titanium alloy and stainless steel using various filler metals," Transactions of Nonferrous Metals Society of China, vol. 22, no. 3, pp. 639-644, 2012.

[19] A. Laik, A. A. Shirzadi, R. Tewari, A. Kumar, and T. Jayakumar, "Microstructure and interfacial reactions during active metal brazing of stainless steel to titanium," Metallurgical and Materials Transactions A, vol. 44, no. 5, pp. 2212-2225, 2013.

[20] A. Elrefaey, L. Wojarski, and W. Tillmann, "Evaluation of corrosion performance of titanium/steel joint brazed by $\mathrm{Cu}$ brazed filler metal," Journal of Materials Engineering and Performance, vol. 21, no. 5, pp. 707-713, 2012.

[21] Y. Zhang, D. Q. Sun, X. Y. Gu, and H. M. Li, "Microstructure and mechanical property improvement of dissimilar metal joints for TC4 Ti alloy to 301L stainless steel," Journal of Materials Science, vol. 53, no. 4, pp. 2942-2955, 2018.

[22] V. I. Isaev, A. N. Cherepanov, and V. P. Shapeev, "Modeling of laser welding of steel and titanium plates with a composite insert," in Proceedings of the XXV Conference on High-Energy Processes in Condensed Matter, Moscow, Russia, 2017.

[23] J. Ning, L. J. Zhang, G. C. Jiang, M. X. Xie, X. Q. Yin, and J. X. Zhang, "Narrow gap multi-pass laser butt welding of explosion welded CP-Ti/Q235B bimetallic sheet by using a copper interlayer," Journal of Alloys and Compounds, vol. 701, pp. 587-602, 2017.

[24] Y. Zhang, D. Q. Sun, X. Y. Gu, and Y. J. Liu, "Nd/YAG pulsed laser welding of TC4 titanium alloy to 301L stainless steel via pure copper interlayer," International Journal of Advanced Manufacturing Technology, vol. 90, no. 1-4, pp. 953-961, 2017.

[25] S. H. Chen, M. X. Zhang, J. H. Huang, C. J. Cui, H. Zhang, and X. K. Zhao, "Microstructures and mechanical property of laser butt welding of titanium alloy to stainless steel," Materials and Design, vol. 53, no. 1, pp. 504-511, 2014.

[26] B. G. Zhang, T. Wang, G. Q. Chen, and J. C. Feng, "Contact reactive joining of TA15 and 304 stainless steel via a copper interlayer heated by electron beam with a beam deflection," 
Journal of Materials Engineering and Performance, vol. 21, no. 10, pp. 2067-2073, 2012.

[27] I. Tomashchuk, P. Sallamand, N. Belyavina, and M. Pilloz, "Evolution of microstructures and mechanical properties during dissimilar electron beam welding of titanium alloy to stainless steel via copper interlayer," Materials Science and Engineering A, vol. 585, no. 12, pp. 114-122, 2013.

[28] T. Wang, B. G. Zhang, J. C. Feng, and Q. Tang, "Effect of a copper filler metal on the microstructure and mechanical properties of electron beam welded titanium-stainless steel joint," Materials Characterization, vol. 73, no. 7, pp. 104-113, 2012.

[29] I. Tomashchuk, P. Sallamand, H. Andrzejewski, and D. Grevey, "The formation of intermetallics in dissimilar Ti6Al4V/copper/AISI316L electron beam and Nb:YAG laser joints," Intermetallics, vol. 19, no. 10, pp. 1466-1473, 2011.

[30] T. Wang, B. G. Zhang, G. Q. Chen, and J. C. Feng, "High strength electron beam welded titanium-stainless steel joint with $\mathrm{V} / \mathrm{Cu}$ based composite filler metals," Vacuum, vol. 94, no. 6, pp. 41-47, 2013.

[31] T. Wang, B. G. Zhang, and J. C. Feng, "Microstructures and mechanical properties of electron beam-welded titanium-steel joints with vanadium, nickel, copper and silver filler metals," Journal of Materials Engineering and Performance, vol. 23, no. 4, pp. 1498-1504, 2014.

[32] M. Eroglu, T. I. Khan, and N. Orhan, "Diffusion bonding between Ti-6Al-4V alloy and microduplex stainless steel with copper interlayer," Materials Science and Technology, vol. 18, no. 1, pp. 68-72, 2002.

[33] M. Ferrante and E. V. Pigoretti, "Diffusion bonding of TI$6 \mathrm{AL}-4 \mathrm{~V}$ to AISI $316 \mathrm{~L}$ stainless steel: mechanical resistance and interface microstructure," Journal of Materials Science, vol. 37, no. 13, pp. 2825-2833, 2002.

[34] A. B. Mukherjee, A. Laik, V. Kain, and J. K. Chakravartty, "Shrinkage-stress assisted diffusion bonds between titanium and stainless steel: a novel technique," Journal of Materials Engineering and Performance, vol. 25, no. 10, pp. 4425-4436, 2016.

[35] S. Kundu, S. Chatterjee, D. Olson, and B. Mishra, "Interface microstructure and strength properties of the diffusionbonded joints of titanium $\mid \mathrm{Cu}$ interlayer| stainless steel," Metallurgical and Materials Transactions A, vol. 39, no. 9, pp. 2106-2114, 2008.

[36] C. G. O. Iii and C. D. Sorensen, "Overview of transient liquid phase and partial transient liquid phase bonding," Journal of Materials Science, vol. 46, no. 16, pp. 5305-5323, 2011.

[37] S. Somasundaram, R. Krishnamurthy, and H. Kazuyuki, "Effect of process parameters on microstructural and mechanical properties of Ti-SS 304L explosive cladding," Journal of Central South University, vol. 24, no. 6, pp. 1245-1251, 2017.

[38] Q. L. Chu, M. Zhang, J. H. Li, and C. Yan, "Experimental and numerical investigation of microstructure and mechanical behavior of titanium/steel interfaces prepared by explosive welding," Materials Science and Engineering A, vol. 689, pp. 323-331, 2017.

[39] M. Gloc, M. Wachowski, T. Plocinski, and K. J. Kurzydlowski, "Microstructural and microanalysis investigations of bond titanium grade1/low alloy steel st52-3N obtained by explosive welding," Journal of Alloys and Compounds, vol. 671, pp. 446-451, 2016.

[40] P. Manikandan, K. Hokamoto, M. Fujita, K. Raghukandan, and R. Tomoshigee, "Control of energetic conditions by employing interlayer of different thickness for explosive welding of titanium/304 stainless steel," Journal of Materials Processing Technology, vol. 195, no. 1-3, pp. 232-240, 2008.

[41] M. Kimura and A. Fuji, "Characteristics of pure-titanium and low carbon steel friction-welded joint with post-weld heat treatment," Materials Science and Technology, vol. 32, no. 10, pp. 1016-1024, 2016.

[42] H. G. Dong, L. Z. Yu, D. W. Deng, W. L. Zhou, and C. Dong, "Effect of post-weld heat treatment on properties of friction welded joint between TC4 titanium alloy and 40Cr steel rods," Journal of Materials Science and Technology, vol. 31, no. 9, pp. 962-968, 2015.

[43] M. Kimura, T. Iijima, M. Kusaka, K. Kaizu, and A. Fuji, "Joining phenomena and tensile strength of friction welded joint between Ti-6Al-4V titanium alloy and low carbon steel," Journal of Manufacturing Processes, vol. 24, pp. 203-211, 2016.

[44] A. Astarita, F. Scherillo, M. Curioni et al., "Study of the linear friction welding process of dissimilar Ti-6Al-4V-stainless steel joints," Materials and Manufacturing Processes, vol. 31, no. 16, pp. 2115-2122, 2016.

[45] X. Li, J. L. Li, Z. X. Liao, F. Jin, F. S. Zhang, and J. T. Xiong, "Microstructure evolution and mechanical properties of rotary friction welded TC4/SUS321 joints at various rotation speeds," Materials and Design, vol. 99, pp. 26-36, 2016.

[46] P. Li, J. L. Li, M. Salman, L. Liang, J. T. Xiong, and F. S. Zhang, "Effect of friction time on mechanical and metallurgical properties of continuous drive friction welded Ti6Al4V/ SUS321 joints," Materials and Design, vol. 56, no. 4, pp. 649-656, 2014.

[47] C. H. Muralimohan, V. Muthupandi, and K. Sivaprasad, "Properties of friction welding titanium-stainless steel joints with a nickel interlayer," Procedia Materials Science, vol. 5, no. 5, pp. 1120-1129, 2014.

[48] H. G. Dong, Z. L. Yang, Z. R. Wang, D. W. Deng, and C. Dong, "Vacuum brazing TC4 titanium alloy to 304 stainless steel with $\mathrm{Cu}-\mathrm{Ti}-\mathrm{Ni}-\mathrm{Zr}-\mathrm{V}$ amorphous alloy foil," Journal of Materials Engineering and Performance, vol. 23, no. 10, pp. 3770-3777, 2014.

[49] W. Li, L. Yan, S. Karnati et al., "Ti-Fe intermetallics analysis and control in joining titanium alloy andstainless steel by laser metal deposition," Journal of Materials Processing Technology, vol. 242, pp. 39-48, 2017.

[50] E. M. Ananwa, "Using taguchi method to optimize welding pool of dissimilar laser-welded components," Optics and Laser Technology, vol. 40, no. 2, pp. 379-388, 2008.

[51] H. C. Chen, G. J. Bi, B. Y. Lee, and C. K. Cheng, "Laser welding of $\mathrm{CP} \mathrm{Ti}$ to stainless steel with different temporal pulse shapes," Journal of Materials Processing Technology, vol. 231, pp. 58-65, 2016.

[52] T. Wang, B. G. Zhang, G. Q. Chen, J. C. Feng, and Q. Tang, "Electron beam welding of Ti-15-3 titanium alloy to 304 stainless steel with copper interlayer sheet," Transactions of Nonferrous Metals Society of China, vol. 20, no. 10, pp. 1829-1834, 2010.

[53] N. Kahraman and B. Gulenc, "Microstructural and mechanical properties of $\mathrm{Cu}$-Ti plates bonded through explosive welding process," Journal of Materials Processing Technology, vol. 169 , no. 1 , pp. $67-71,2005$.

[54] J. H. Han, J. P. Ahn, and M. C. Shin, "Effect of interlayer thickness on shear deformation behavior of AA5083 aluminum alloy/SS41 steel plates manufactured by explosive welding," Journal of Materials Science, vol. 38, no. 1, pp. 13-18, 2003.

[55] X. J. Yuan, K. L. Tang, Y. Q. Deng, J. Luo, and G. M. Sheng, "Impulse pressuring diffusion bonding of a copper alloy to 
a stainless steel with/without a pure nickel interlayer," $M a$ terials and Design, vol. 52, no. 24, pp. 359-366, 2013.

[56] Q. Shen, H. Y. Xiang, Q. Q. Luo, X. P. Su, and L. M. Zhang, "Interfacial microstructure and mechanical properties of diffusion bonded $\mathrm{TC}_{4} / 0 \mathrm{Cr}_{18} \mathrm{Ni}_{9} /$ oxygen free copper joints," Materials and Design, vol. 50, pp. 230-234, 2013.

[57] W. S. Liu, L. P. Long, Y. Z. Ma, and L. Wu, "Microstructure evolution and mechanical properties of $\mathrm{Mg} / \mathrm{Al}$ diffusion bonded joints," Journal of Alloys and Compounds, vol. 643, pp. 34-39, 2015.

[58] S. Kundu and S. Chatterjee, "Interface microstructure and strength properties of diffusion bonded joints of titanium-Al interlayer-18Cr-8Ni stainless steel," Materials Science Engineering: A, vol. 527, no. 10-11, pp. 2714-2719, 2010.

[59] C. H. Muralimohan, M. Ashfaq, R. Ashiri, V. Muthupandi, and K. Sivaprasad, "Analysis and characterization of the role of Ni interlayer in the friction welding of titanium and 304 austenitic stainless steel," Metallurgical and Materials Transactions A, vol. 47, no. 1, pp. 347-359, 2016.

[60] C. Velmurugan, V. Senthilkumar, S. Sarala, and J. Arivarasan, "Low temperature diffusion bonding of Ti-6Al-4V and duplex stainless steel," Journal of Materials Processing Technology, vol. 234, pp. 272-279, 2016.

[61] M. Ghosh and S. Chatterjee, "Characterization of transition joints of commercially pure titanium to 304 stainless steel," Materials Characterization, vol. 48, no. 5, pp. 393-399, 2002.

[62] T. Vigraman, D. Ravindran, and R. Narayanasamy, "Effect of phase transformation and intermetallic compounds on the microstructure and tensile strength properties of diffusionbonded joints between Ti-6Al-4V and AISI 304L," Materials and Design, vol. 36, pp. 714-727, 2012.

[63] A. Miriyev, D. Barlam, R. Shneck, A. Stern, and N. Frage, "Steel to titanium solid state joining displaying superior mechanical properties," Journal of Materials Processing Technology, vol. 214, no. 12, pp. 2884-2890, 2014.

[64] S. Kundu, S. Sam, and S. Chatterjee, "Interface microstructure and strength properties of Ti-6Al-4V and microduplex stainless steel diffusion bonded joints," Materials and Design, vol. 32, no. 5, pp. 2997-3003, 2011.

[65] A. Miriyev, M. Sinder, and N. Frage, "Thermal stability and growth kinetics of the interfacial $\mathrm{TiC}$ layer in the $\mathrm{Ti}$ alloy/ carbon steel system," Acta Materialia, vol. 75, pp. 348-355, 2014.

[66] S. Simoes, F. Viana, A. S. Ramos, M. T. Vieira, and M. F. Vieira, "Reaction-assisted diffusion bonding of TiAl alloy to steel," Materials Chemistry and Physics, vol. 171, pp. 73-82, 2016.

[67] P. He, J. C. Feng, B. G. Zhang, and Y. Y. Qian, “A new technology for diffusion bonding intermetallic TiAl to steel with composite barrier layers," Materials Characterization, vol. 50, no. 1, pp. 87-92, 2003.

[68] J. Zhang, Q. Shen, G. Q. Luo, M. J. Li, and L. M. Zhang, "Microstructure and bonding strength of diffusion welding of $\mathrm{Mo} / \mathrm{Cu}$ joints with $\mathrm{Ni}$ interlayer," Materials and Design, vol. 39, pp. 81-86, 2012.

[69] M. I. Barrena, J. M. G. D. Salazar, N. Merino, and L. Matesanz, "Characterization of $\mathrm{WC}-\mathrm{Co} / \mathrm{Ti}_{6} \mathrm{Al}_{4} \mathrm{~V}$ diffusion bonding joints using $\mathrm{Ag}$ as interlayer," Materials Characterization, vol. 59, no. 10, pp. 1407-1411, 2008.

[70] A. Ghoneim and O. Ojo, "Asymmetric diffusional solidification during transient liquid phase bonding of dissimilar materials," Metallurgical and Materials Transactions A, vol. 43, no. 3, pp. 900-911, 2012.
[71] E. Norouzi, M. Atapour, M. Shamanian, and A. Allafchian, "Effect of bonding temperature on the microstructure and mechanical properties of Ti-6Al-4V to AISI 304 transient liquid phase bonded joint," Materials and Design, vol. 99, pp. 543-551, 2016.

[72] E. Norouzi, M. Atapour, M. Shamanian, and B. Khosravi, "Diffusion brazing of Ti-6Al-4V and AISI 304: an EBSD study and mechanical properties," Journal of Materials Science, vol. 52, no. 20, pp. 12467-12475, 2017.

[73] E. Norouzi, M. Atapour, and M. Shamanian, "Effect of bonding time on the joint properties of transient liquid phase bonding between Ti-6Al-4V and AISI 304," Journal of Alloys and Compounds, vol. 701, pp. 335-341, 2017.

[74] Y. Zhou, "Analytical modeling of isothermal solidification during transient liquid phase (TLP) bonding," Journal of Materials Science Letters, vol. 20, no. 9, pp. 841-844, 2001.

[75] S. Zakipour, M. Samavatian, A. Halvaee, A. Amadeh, and A. Khodabandeh, "The effect of interlayer thickness on liquid state diffusion bonding behavior of dissimilar stainless steel 316/Ti-6Al-4V system," Materials Letters, vol. 142, pp. 168171, 2015.

[76] S. Zakipour, A. Halvaee, A. Amadeh, M. Samavatian, and A. Khodabandeh, "An investigation on microstructure evolution and mechanical properties during transient liquid phase bonding of stainless steel 316L to Ti-6Al-4V," Journal of Alloys and Compounds, vol. 626, pp. 269-276, 2015.

[77] A. Yildı, Y. Kaya, and N. Kahraman, "Joint properties and microstructure of diffusion-bonded grade 2 titanium to AISI 430 ferritic stainless steel using pure $\mathrm{Ni}$ interlayer," International Journal of Advanced Manufacturing Technology, vol. 86, no. 5-8, pp. 1287-1298, 2016.

[78] B. Szwed and M. Konieczny, "Microstructure and mechanical properties of joints of titanium with stainless steel performed using nickel filler," Archives of Metallurgy and Materials, vol. 61, no. 2, pp. 997-1001, 2016.

[79] S. Sam, S. Kundu, and S. Chatterjee, "Diffusion bonding of titanium alloy to micro-duplex stainlesssteel using a nickel alloy interlayer: interface microstructure and strength properties," Materials and Design, vol. 40, pp. 237-244, 2012.

[80] S. Kundu, B. Mishra, D. L. Olson, and S. Chatterjee, "Interfacial reactions and strength properties of diffusion bonded joints of Ti64 alloy and 17-4PH stainless steel using nickel alloy interlayer," Materials and Design, vol. 51, no. 5, pp. 714-722, 2013.

[81] X. J. Yuan, G. M. Sheng, B. Qin, W. Z. Huang, and B. Zhou, "Impulse pressuring diffusion bonding of titanium alloy to stainless steel," Materials Characterization, vol. 59, no. 7, pp. 930-936, 2008.

[82] F. L. Wang, G. M. Sheng, and Y. Q. Deng, "Impulse pressuring diffusion bonding of titanium to 304 stainless steel using pure Ni interlayer," Rare Metals, vol. 35, no. 4, pp. 331-336, 2016.

[83] Y. Q. Deng, G. M. Sheng, and C. Xu, "Evaluation of the microstructure and mechanical properties of diffusion bonded joints of titanium to stainless steel with a pure silver interlayer," Materials and Design, vol. 46, no. 4, pp. 84-87, 2013.

[84] M. Balasubramanian, "Application of Box-Behnken design for fabrication of titanium alloy and 304 stainless steel joints with silver interlayer by diffusion bonding," Materials and Design, vol. 77, no. 1, pp. 161-169, 2015.

[85] S. Kundu, G. Thirunavukarasu, S. Chatterjee, and B. Mishra, "Effect of bonding temperature on phase transformation of diffusion-bonded joints of duplex stainless steel and Ti-6Al$4 \mathrm{~V}$ using nickel and copper as composite intermediate 
metals," Metallurgical and Materials Transactions A, vol. 46, no. 12, pp. 5756-5771, 2015.

[86] M. K. Lee, J. G. Lee, Y. H. Choi et al., "Interlayer engineering for dissimilar bonding of titanium to stainless steel," Materials Letters, vol. 64, no. 9, pp. 1105-1108, 2010.

[87] P. Li, J. L. Li, J. T. Xiong, F. S. Zhang, and S. H. Raza, "Diffusion bonding titanium to stainless steel using $\mathrm{Nb} / \mathrm{Cu} / \mathrm{Ni}$ multi-interlayer," Materials Characterization, vol. 68, pp. 82-87, 2012.

[88] Q. L. Chua, M. Zhang, J. H. Li, Q. Y. Fan, W. W. Xie, and Z. Y. Bi, "Joining of CP-Ti/Q345 sheets by Cu-based filler metal and effect on interface," Journal of Materials Processing Technology, vol. 225, pp. 67-76, 2015.

[89] Y. Jing, Q. Q. Yang, W. H. Xiong, B. Huang, B. L. Li, and M. Zhang, "Microstructure and shear strength of brazed joints between $\mathrm{Ti}(\mathrm{C}, \mathrm{N})$-based cermet and steel with $\mathrm{Cu}$-Ag-Ti filler metal," Journal of Alloys and Compounds, vol. 682, pp. 525530, 2016.

[90] T. F. Song, X. S. Jiang, Z. Y. Shao et al., "Microstructure and mechanical properties of vacuum diffusion bonded joints between Ti-6Al-4V titanium alloy and AISI316L stainless steel using $\mathrm{Cu} / \mathrm{Nb}$ multi-interlayer," Vacuum, vol. 145, pp. 68-76, 2017. 


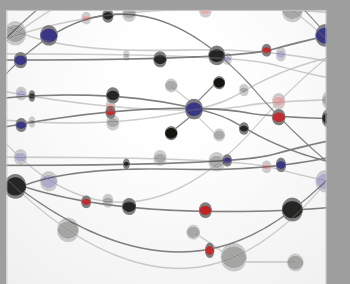

The Scientific World Journal
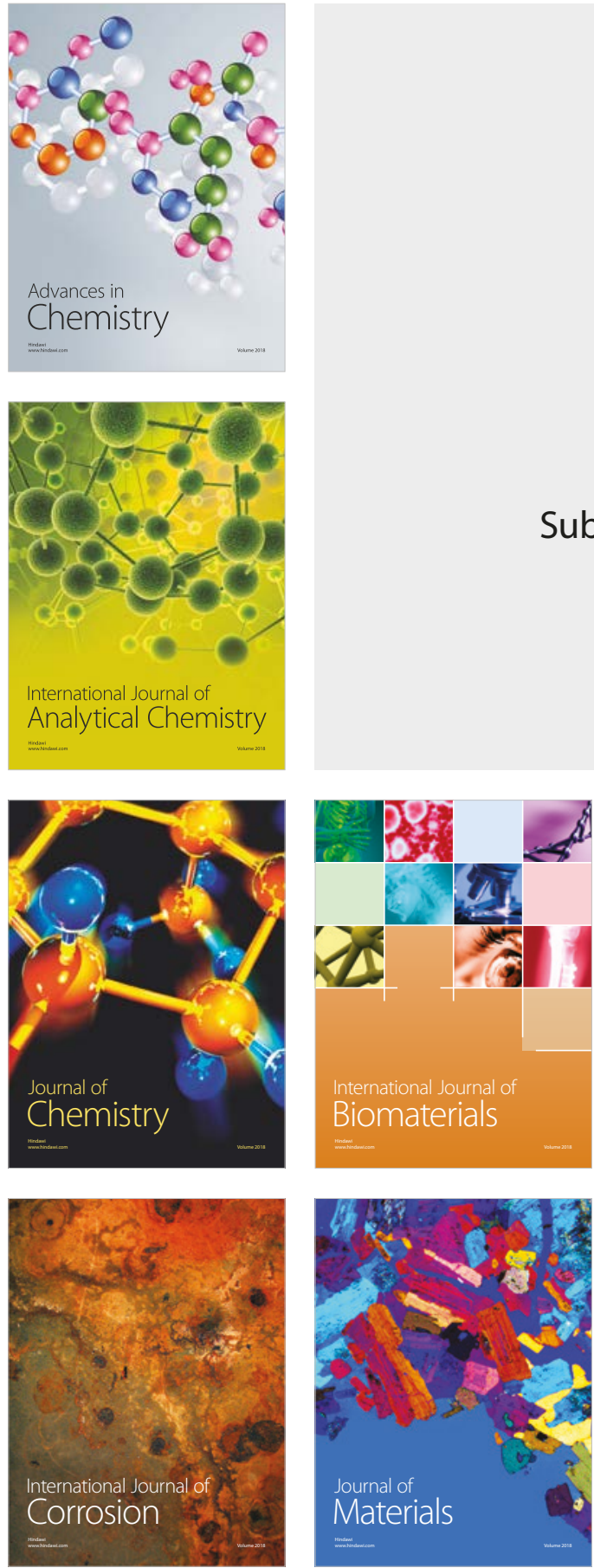

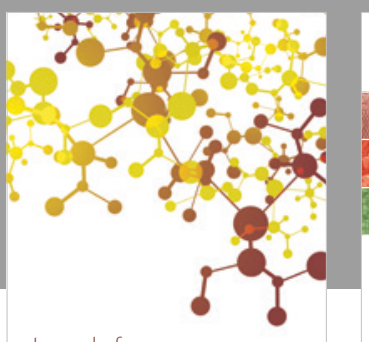

Journal of

Applied Chemistry
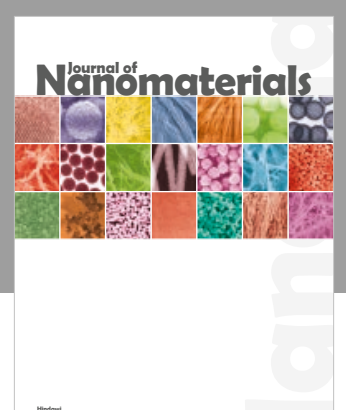

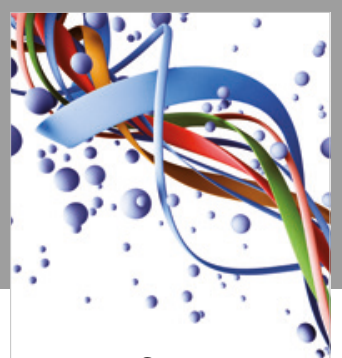

Scientifica

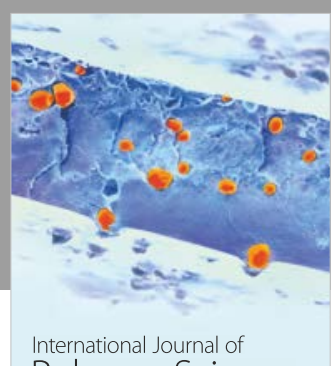

Polymer Science

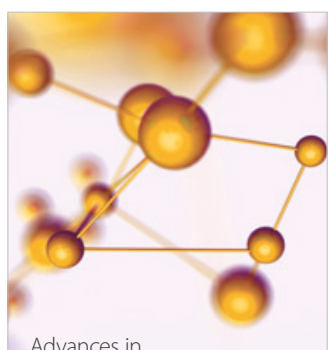

Physical Chemistry
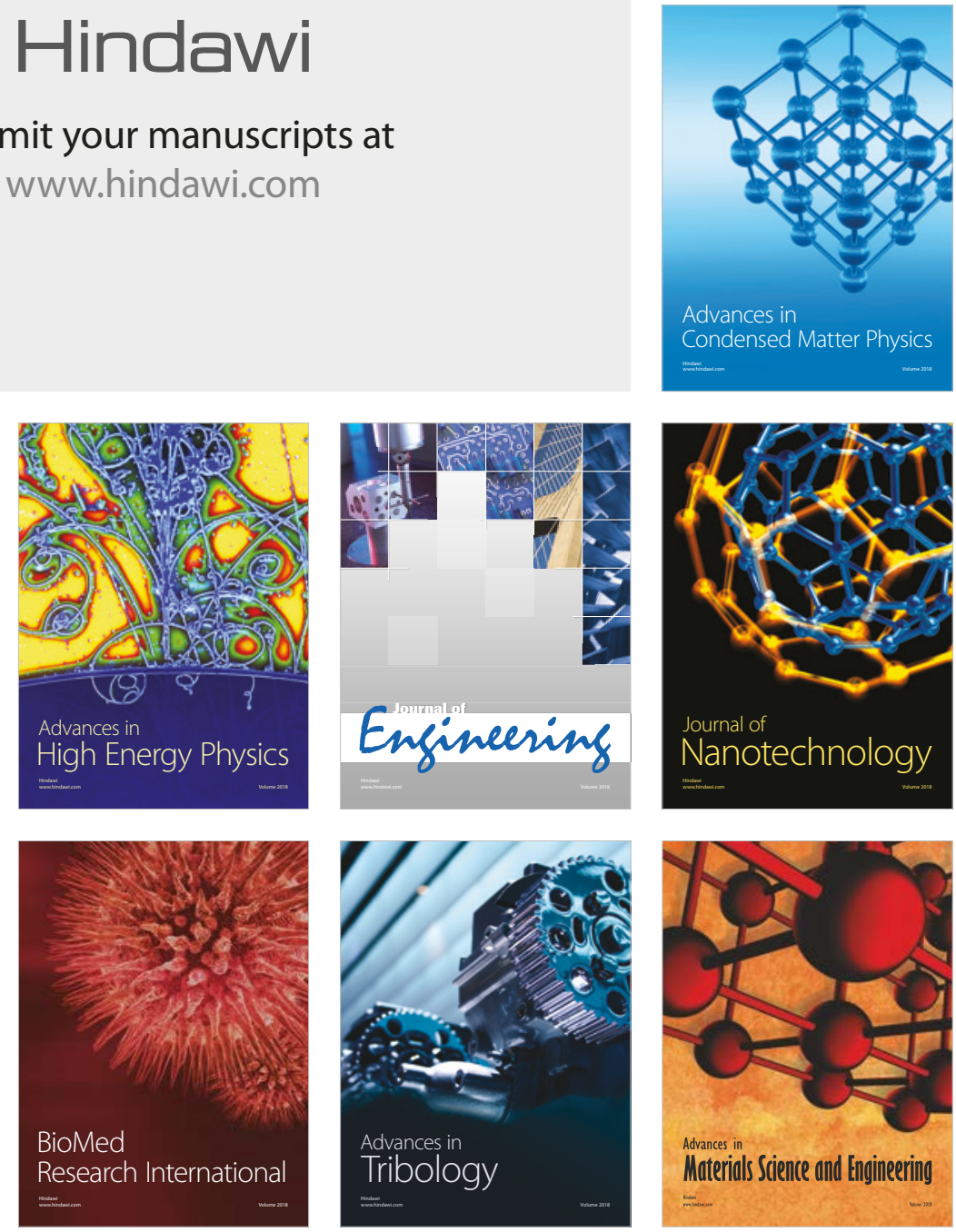